\title{
STEEL SEISMIC DESIGN
}

\author{
G. W. Butcher \\ This paper is a revision of a paper from the proceedings of a seminar on \\ "Seismic Problems in Structural Engineering" arranged by the Departments \\ of Civil Engineering and Extension Studies of the University of \\ Canterbury held in Christchurch from 13 - 16 May 1968.
}

\section{SUMMARY:}

Structural steel has proved to be a suitable material for ductile moment resisting space frames in buildings subjected to strong earthquake ground motions.

The material properties considered necessary to avoid premature failure before the beneficial inelastic potential of the material is achieved are discussed. Consideration is also given to low cycle fatigue, connections, design methods, workmanship and inspection.

\section{Introduction}

This Paper deals with multi-storey steel moment resisting space frames of conventional type composed basically of rolled universal beam and column sections as the principal elements.

As with ductile moment resisting space frames of other materials subjected to strong earthquake ground motions, economy requires that the energy absorption capacity of the system be fully utilised as the basis of design, rather than criteria of strength alone. Energy dissipation is achieved by the ability to deform well into the inelastic range. current methods of design of multi-storey structures to resist earthquake motions are based upon the strong column - weak beam concept. This postulates that the survival of a building during an earthquake depends largely upon the ability of the beams to dissipate energy by inelastic action while the columns in the main remain elastic. Energy dissipation is best provided by beams and connections with stable hysteresis loops.

Park (1) has shown the justification for the strong column - weak beam concept as applied to reinforced concrete moment resisting frames. The concept applies equally well to steel framed structures.

There is a considerable volume of theoretical study and research applying to the problems related to inelastic behaviour of steel structures. This has been mainly associated with the application of plastic design methods to steel structures. Plastic design depends upon the ability of the structure to deform well into the inelastic range without fracture or unloading as the deformations increase. The structure and its components must be ductile. Ductility in so far as structural steel is concerned may be regarded as the ability to absorb large plastic deformations without fracture, and includes the initial elastic region, the so called plastic range (more accurately the dynamic jump) and the region of strain hardening. Figure 1 shows these regions on an idealized stress strain curve while Figure 2 shows actual stress strain curves for a mild steel, a low alloy steel and a quenched and tempered steel. Plastic design methods are concerned mainly with monotonic and proportional loadings, but with care the results may be applied to structures subjected to earthquake motions where the beams in particular are subjected to short term dynamic loadings with load reversals in the inelastic range.

The performance of structural steel elements in multistorey frames subjected to actual strong earthquake ground motions has been particularly good. In Anchorage for instance there were a number of multi-storey buildings with structural steel frames designed for gravity loads with shear walls and cores for lateral loads. Typical is the Cordova Building which is a six storey office building approximately 54 feet by 130 feet in plan. It has a full moment resisting structural steel frame in the narrow direction (major axis of universal columns). In the long direction semi-rigid beam column connections only are employed. The lateral forces are resisted by a reinforced concrete core enclosing the lift shaft and stairwell. In the 1964 earthquake damage occurred mainly in the ground floor (although the penthouse suffered severe damage). The core partially failed at ground floor level as did the non structural 4" reinforced concrete curtain walls at each end of the building. Following the failure of the core, the building was subjected to large lateral displacements with the structural steel frame alone furnishing the lateral resistance. The steel frame in the narrow direction at the south end of the building sustained damage whereas the other frames in the building were undamaged. This was due to the following :-

(1) The stiffening effect of an adjacent stairway landing and associated steel framing which greatly stiffened this one column in the three column frame.

(2) The frame was the greatest distance from the centre of rigidity and therefore subjected to torsional effects.

The stiffened column suffered fractures in the flanges but the web remained partly intact allowing the column to shorten by $1 \frac{1}{2} "$ (Figure 3). The remaining columns in the bent yielded 
in the flanges at the first floor beam connections. (Figure 4).

Referring to the Cordova Building, the authors of the report on building damage in Anchorage (Reference(2) comment as follows :-

"The performance of this building in resisting the earthquake forces in the longitudinal

(north-south) direction is striking, especially when compared to the Four Seasons Apartment which is similar in size, height, and method of resisting the longitudinal lateral loads through the use of cantilever core walls and in the length of reinforcing bar laps. In the Cordova Building, after the core partially failed, the semirigid moment connections between the longitudinal beams and the columns apparently had sufficient strength to maintain the stability of the structure after core damage".

A general indication of the total weight of structural steel per square foot in a ductile moment resisting space frame may be obtained from Figure 5. The graph is intended only as an indication of order of magnitude and should be used with caution accordingly.

It is only recently that special requirements for the use of structural steel in stuctures subject to seismic ground motions have been incorporated in codes. In the 1968 revision of the S.E.A.O.C. recommended requirements (Reference (4) more extensive provisions are included than in previous editions which merely specified the grade of steel. The provisions now read :-

Sec. 2313 (j) 2 :

Construction. The necessary ductility for a ductile moment resisting space frame shall be provided by a frame of structural steel conforming to section 2725 of the code, with moment resisting connections. The more important matters covered in section 2725 are:

Materials - generally those suitable for plastic design;

Connections - these are required to develop the full plastic capacity of the beam or girder. An exception is where it can be shown that ductile rotation capacity can be provided with a weaker connection;

Local Buckling - the so called "compact" sections suitable for plastic design should be used;

Slenderness Ratios - the effective length of compression members should be determined on the basis of the unbraced frame, i.e. sidesway permitted condition;

Non-Destructive Weld Testing - non destructive testing should be used on connections with tension butt welds.

These matters and others equally as important are discussed in greater length under the following headings :

Energy Absorption Capacity of structural
Steel

61

Materials

Low Cycle Fatigue

Connections

Design Methods

Workmanship and Welding Inspection.

To conclude these introductory remarks, it should be made clear that the use of structural steel in itself will not ensure completely adequate performance of a structure subjected to strong earthquake ground motions. As with other structural materials, careful attention must be paid to structural concept, selection and testing of materials, adequate design of connections, competent workmanship and inspection procedures for quality control.

\section{Energy Absorption Capacity of Structural Steel}

\subsection{General}

The importance of the inelastic region in absorbing energy can be assessed in a qualitative manner by the behaviour of a hypothetical one inch cube of steel under load. Up to the yield point of $36 \mathrm{kips}$ per square inch the energy stored in the cube is

$$
\begin{aligned}
\text { Us }=\frac{1}{2} \text { stress } \times \text { strain } & =\frac{36,000}{30 \times 10^{6} \times \frac{36,000}{12}} \\
& =1.8 \mathrm{ft} .1 \mathrm{~b} . \text { per cu.in. }
\end{aligned}
$$

If the cube is now stretched to a strain at which strain hardening commences (approximately $0.0012 \times 12=0.0144$ ) then the energy absorbed in plastic deformation is

$$
\begin{aligned}
\mathrm{Ud} & =\frac{36,000}{12}(0.0144-0.0012) \\
& =39.6 \mathrm{ft} .1 \mathrm{~b} . \text { per cu. in. }
\end{aligned}
$$

The actual energy absorbed by members in a frame loaded into the inelastic region is of course considerably different from the rather crude approximation given above. However it can be seen that steel has the ductility necessary to absorb considerable amounts of energy.

A measure of the energy absorbed by the structure is the ductility factor $/$ Park (I)

has defined $\mathcal{M}$ as the ratio of latera 1 deflection at ultimate to lateral deflection at first yield.

\section{$=\mu \Delta u / \Delta \mathrm{y}$}

In addition to the above definition ductility factor has also been defined as the ratio of total deformation to elastic deformation at yield in terms of strain and rotation. The ratio for strain is a function of material while that for rotation is a function of material, shape and size of cross section of the particular member.

When applied to deflections $\mu$ then includes not only the material and member properties but also the structure and load characteristics. The term ductility factor should be 
restricted to the first definition.

\subsection{Rotation Capacity of Sections}

For design purposes we need to know the rotation capacity of a section. In the following only the rotation capacity of steel beams will be discussed. A valuable review of the present state of knowledge (1968) and recommendations for future research is Reference 5 .

As stated in the introduction most of the work in this field has aimed at development of plastic design methods. It has relevance however in the case of seismic design in steel.

In the absence of instability effects failure of a steel beam would take place theoretically by tensile fracture when the ultimate tensile strength of the material was achieved. However residual stress, (in so far as it effects local buckling) local buckling and lateral instability reduce the theoretical moment capacity.

An idealised moment curvature relationship for a universal beam subjected to a moment gradient is shown in Figure 6 . For beams subjected to moment gradient, initial yielding cannot spread until the moment is increased above the moment necessary to cause initial yielaing Mp.

Strain hardening occurs and the actual moment rises above the plastic moment value until local buckling occurs. The increased moment capacity of the beam due to strain hardening is ignored in plastic design.

When local buckling appears well into the inelastic range the moment capacity eventually falls off. Local buckling usually leads to lateral instability and the combined effect is to cause unloading.

In order to assure adequate rotation capacity before local buckling occurs, restrictions have been placed on the beam flange width to thickness ratio. The 1969 A.I.S.C. Specification (6) requires the following minimum values for sections suitable for plastic design.

$\begin{array}{cc}\text { Yield Point } & \text { Flange width/Thickness } \\ 36 & 17 \\ 50 & 14 \\ 65 & 12\end{array}$

The lateral bracing provisions of the A.I.S.C. specification are also relevant in assuring adequate rotation capacity.

Iay and Galambos (7) have developed an expression to prealct the rotation capacity of a universal beam type steel member under moment gradient.

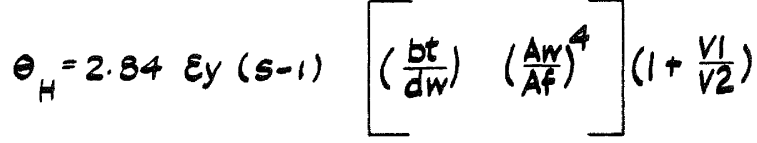

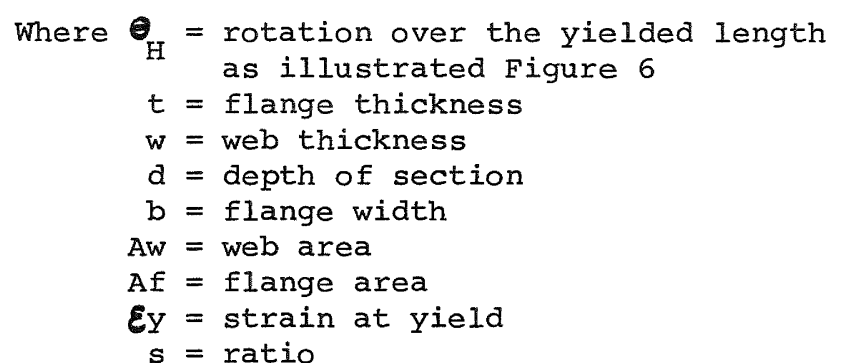

strain at strain hardening strain at yield

$V_{1} \& V_{2}=$ are absolute values of the shears on either side of the hinge

NOTE where yielding takes place in only one member entering a joint then

$$
1+\frac{V_{1}}{V_{2}}=1
$$

Simplifying assumptions were assumed in deriving this expression as to the length of the local buckle and the strain at which local buckling commenced. The rotation capacity predicted from the above expression is conservative.

Actual moment curvature relationships for two types of steel and sections with varying $\mathrm{b} / \mathrm{t}$ ratios are shown in Figure 7 .

These are taken from Reference 8 . A-2 is the curve for a typical mild steel (Fy = $36,000 \mathrm{lb./sq.in.)}$ and $\mathrm{B}-2$ is for a high yield steel (Fy $=50,000 \mathrm{lb} . / \mathrm{sq}$. inc.).

Beams and connections under load reversal have been tested by Bertero and Popov (9) and Pinkney (10)

These tests are discussed later. However even though carried out on cantilevers the tests showed essentially the same behaviour as the monotonic loaded beams discussed earlier. Local buckling occurred in the compression flange in the inelastic range but tended to straighten out when the load was reversed and the flange under tension. Failure criterion was fracture caused by low-cycle fatigue in the area of local buckling. A view of the local buckles in the flange are shown in Figure 8. No lateral instability was observed.

calambos (5) states that an examination of the inelastic rotations from this particular series of tests showed that beam rotations were about $40 \%$ greater than the rotation predicted by the formula given above.

The inelastic behaviour of steel beams may be represented by the ordinary elastoplastic load-displacement hysteresis curve (see Figure 9a). That steel roughly fits this assumption may be seen by comparing this to actual hysteresis loons from tests carried out by Popov and Pinkney (10) It is useful also to compare these to the ordinary degrading stiffness hysteresis curves appropriate to reinforced concrete (Figure 9b)

In fact steel has a transition curve between the elastic and inelastic branches. The large areas of the loops indicate good 
energy absorption properties.

\section{Materials}

The selection of materials to be used in the structure is an important part of the design process.

In general, for a steel framed structure, stress or deflection criteria govern the choice of a particular section for a member in the frame. If stress governs then consideration should be given to the use of a steel with a higher yield point. However structural steel should not be selected by yield point alone. Steels for earthquake resistant, multi-storey frames should be those accepted as suitable for plastic design.

In selecting a steel the following matters require consideration:

(1) Strength and Ductility

(2) Weldability

(3) Resistance to Brittle Fracture - Notch Ductility.

\subsection{Strength and Durability}

Weldable structural steels normally available ex stock or on indent in New Zealand are usually supplied in accordance with B.S. 4360: or Australian Standards A.135, A.147, A.149, A.151 etc. B.S. 4360 (11) or includes steels in four tensile grades with several subgrades in each grade distinguished by increasing yield stress and notch ductile requirements. The main mechanical and chemical properties applying to plate are summarised in Table 1 .

\subsection{Weldability}

We may define weldability of a steel as the relative ease with which two pieces may be joined together in a satisfactory manner by welding. The weldability of a particular steel cannot be assessed on the basis of chemical composition alone. Other important factors which affect weldability are design details, welding process, materials and procedure including preheat, service environment, the standard of welding, and the quality of inspection. The material factors have been generally considered in the preparation of B.S. 4360. B.S. $1856^{(12)}$ and B.S. $2642^{(13)}$ cover requirements for arc welding of steels to Grades 40 and 43 and Grades 50 to 55 respectively. In addition to these published guides laboratory cracking and similar tests may be carried out to evaluate materials and particlar problems. However the only truly reliable test is to actually fabricate a joint under the conditions likely to be encountered in the fabrication of the structure.

The concept of the carbon equivalent has been used to relate the hardness of the heat affected zone (HAZ) with the chemical composition of a steel. The hardness of the HAZ becomes greater as the carbon equivalent
- ncreases. The carbon equivalent is arrived at by giving each alloying element a coefficient related to the equivalent amount of carbon. The carbon equivalent used in B.S. 4360 is

C.E. $=\mathrm{C}+\frac{\mathrm{Mn}}{6}+\frac{\mathrm{Cr}+\mathrm{Mo}+\mathrm{V}}{5}+\frac{\mathrm{Ni}+\mathrm{Cu}}{15}$.

Steels with a high carbon equivalent tend to be more difficult to weld successfully since they have a greater tendency for cracking in the HAZ.

Cracking in the HAZ usually takes the form of toe and under bead cracking. The four main factors affecting the susceptibility of steel to $\mathrm{HAZ}$ cracking are the composition of the steel, the rate of cooling, the presence of hydrogen and the state of stress. The cooling rate and steel composition determine the type of micro-structure. The purpose of pre-heating is to decrease the cooling rate. The slower cooling rate has the effect of minimising the formation of a hardened structure in the HAZ and of allowing hydrogen more opportunity to disperse by diffusion, thus reducing the affective hydrogen content in the $\mathrm{HAZ}$. Information on preheat requirements is included in B.S. 1856 and B.S. 2642. The presence of hydrogen in the HAZ may also be reduced by the use of low hydrogen electrodes and the baking of electrodes before use. The preheat also has the effect of drying off the surfaces of the joint to be welded and hence reducing the possibility of hydrogen being present.

Welding stresses and high restraint can lead to problems of lamellar tearing of plate under certain circumstances. Thicker plates of the order of $1 \frac{1}{2}$ " and over in beam column junctions where welds are made at right angles to the direction of rolling are particularly susceptible to this problem. During the rolling of steel a flow structure is imparted to the material as a result of non metallic inclusions rolled out into layers in the direction of rolling. The mechanical properties in the thickness of the material are therefore totally different to those in the direction of rolling. The susceptibility of steel to this type of defect increases with increasing plate thickness.

\subsection{Brittle Fracture}

Brittle fracture may be defined simply as rupture with no apparent permanent deformation or energy absorption. Distinguishing features are :

(1) The absence of deformation of the material in the vicinity of fracture;

(2) The fracture plane with few exceptions is at $90^{\circ}$ to the plate or section surface;

(3) Characteristic surface markings are present.

Brittle fracture is not limited to welded structures. There are reports of brittle 
fracture in steel structures going back to the last half of the 19th century when steel was first being used as a constructional material. one of the earliest recorded examples of a brittle fracture mode of failure is that of a rivetted steel water stand-pipe on Long Island. This structure failed during its hydrostatic acceptance test on 7 th October 1886. Another early example is the catastrophic failure of a rivetted steel tank containing 2 million gallons of molasses, due to brittle fracture. This occurred on 15th January 1919 in Boston with ambient temperatures at freezing. More recent failures affecting welded structures are; the collapse of bridges over the Albert Canel in Belgium in the late $1930^{\prime} \mathrm{s}$ and 1940; the failure of a number of welded ships during World war II and more recently the celebrated partial collapse due to brittle fracture of a span of Kings Bridge in Melbourne, Australia.

Conditions which favour a brittle fracture mode of failure are :

(1) A low temperature;

(2) A high level of stress (including residual stress);

(3) A notch crack or sharp discontinuity producting conditions of triaxial stress, and therefore high strain rates.

Brittle fracture in building structures is comparatively rare. There may be a number of reasons why this should be so but it would be unwise to conclude that steel building frames may be considered immune from this type of failure.

\section{The literature (14) records the} failure of a test knee connection composed of very large members ( 36 WF 230) due to brittle fracture. The average flange thickness was $1 \frac{1}{4} "$ but no precautions were taken to preheat the joint or to use special welding procedures. The connection was first loaded in "compression" (re-entrant corner in compression) and subsequently loaded in the "tension" mode. The failure occurred in the HAZ during the tension loading.

Some cases of spontaneous brittle fracture of rolled sections in the absence of external loading have been reported. An example of this type of fracture is shown in Figure 11.

The response of a frame to earthquake ground motions could increase the chances of brittle fracture in service for the following reasons :

(1) Far more extensive use is now being made of welding.

(2) Steel is a rate sensitive material. High strain rates from dynamic loading have the same effect as raising the transition temperature.

(3) Heavy moment connections are required involving greater restraint and increasing the possibility of triaxial stress conditions.

(4) Taller moment resisting frames are now being used requiring thicker rolled sections and plates.

B.S. 449: 1959, Amendment No. 6, June 1966 leaves no doubts about the necessity for precautions against brittle fracture where welded elements are used. The amendment prohibits the use of steel to the old B.S. 15 in thicknesses over $1 \frac{1}{2} "$ and sets out impact test requirements for other steels. In addition, designers are warned to give further consideration to requirements where single failure would be catastrophic, where complicated details are involved under dynamic loadings and where service temperatures are low.

In the engineering sense stress rates for building response to earthquake ground motions can be relatively high and of the order of 250 kips per square inch per second. Typical observed stress rates for other structures are (Reference 16):

(1) Crane girder $12 \mathrm{kips}$ per square inch per second;

(2) Railway bridge 350 Kips per square inch per second;

(3) Highway bridge 57 Kips per square inch per second.

isteels which have a high resistance to the brittle fracture mode of failure are termed notch ductile steels. We may define notch ductility as the ability of the steel to deform in a ductile manner in the presence of a notch. Notch ductility is influenced by the metallurgy of the steel, the rolling techniques and the material thickness.

For the normal structural steels the metallurgical aspects which are important are those that control grain size. Elements which have significant beneficial effect are manganese and nickel as they produce finer grain sizes. In addition finely dispersed aluminium nitride and some niobium and vanadium nitrides and carbides also produce a fine grain structure.

Rolling techniques and thickness also affect grain size. Thick plates are often finished at relatively high temperatures and cool more slowly, resulting in a coarse grain size and lower notch ductility. Controlled rolling may be used to achieve grain size reduction and hence improved notch ductility. This process consists of rolling to $70 \%$ of total required reduction, cooling to about $950^{\circ} \mathrm{c}$. then rolling to final dimensions with the finishing temperature about $850^{\circ} \mathrm{C}$.

A heat treatment called normalizing may also be used to improve notch ductility. Normalizing consists of heating the steel to $900-950^{\circ} \mathrm{C}$. and then cooling in air. This not only achieves grain size reduction but also renders the structure more uniform. 
The effect of adjusting the chemistry, thickness, controlled rolling and normalising on the notch ductility of two types of steel are clearly shown in Fiqure 12 and the accompanying table, (17). The best known test for measuring notch ductile properties of a steel is the charpy $V$ notch impact test. The principle of this test is shown in Figure 13. Tests are carried out at different temperatures permitting the plotting of transition curves of energy and percentage fibrosity or crystallinity against temperature. The transition temperatures are recorded for a given energy value, say $35 \mathrm{ft}$. $1 \mathrm{~b}$. and the $50 \%$ crystalline appearance of the fracture specimen. Idealized curves are shown in figure 14 and may be compared to transition curves for notch ductile steels from Figure 15 (18).

Empirical relationships between the energy level in the charpy test and the actual service performance have been established. Tipper (19). however has shown that there is very little agreement on whether such relationships are valid. In addition a particular energy level criteria does not provide the same guarantee against brittle fracture for all types of steel. In general it would seem more desirable to have a $50 \%$ fibrosity transition temperature for the steel as low as possible rather than an energy level criteria.

The transition temperature approach to notch ductility based upon dynamic fracture tests such as the Charpy $V$ notch test have the advantage of being rapid and simple. Fracture mechanics has been applied to this problem by various investigators who have developed a number of large size tests. The most widely used is the Drop Weight Test developed by Pellini (20) From this test the Nil Ductility Temperature (NDT) may be determined which is the highest temperature at which failure propagates to the edge of the specimen.

The large size of the test pieces and expense involved together with other considerations limit the usefulness of such fracture mechanics tests to laboratory and research tests. The dynamic tests may be correlated with the fracture mechanics test for a particular steel. The dynamic test may then be used as a quality control test for the production of the steel concerned.

The designer can make use of the transition temperature concept together with Fracture Analysis Diagrams (reference diagrams which relate flaw size - stress relationships for fracture initiation in the transition range) to assess whether brittle fracture will be a problem or not.

\section{Low Cycle Fatigue}

Steel seismic design must consider the behaviour of the material when subjected to a number of cycles of fully or partially reversed loading in the inelastic range. The number of such load reversals during a typical earthquake may be 10 to 15 with strains of the order of plus or minus $1 \frac{1}{2} \%$.

Gurney (21)

suggests that the rate of crack propagation is the most important characteristic for steel structures subjected to low cycle fatigue and in particular welded structures. Low cycle fatigue life may be regarded as consisting of a crack initiation period followed by a propagation period. However if a structure contains defects essentiaIIy the same as initiated cracks in the regions of high strain, the initiation period is for all practical purposes eliminated. The low cycle fatigue life of such a structure might therefore consist only of a crack propagation period with failure ensuing when the crack reaches the critical size for fast fracture. Gurney also shows from theoretical considerations and tests that under conditions of reversed loading the relationship between total plastic strain and number of cycles may be expressed as follows :

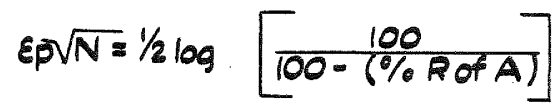

where $\varepsilon_{p}=$ total plastic strain $\mathrm{N}=$ number cycles

$\% \mathrm{R}$ of $\mathrm{A}=$ percentage reduction of area in a tensile test.

This relationship implies that material strength is not significant in defining low cycle fatigue behaviour. The main requirement is a material with good ductility. As discussed previously Bertero and Popov (9) have carried out tests on steel cantilevered beams to determine the low cycle fatigue life of such beams in the inelastic range. In these tests a 4" $\times$ 4" wide flange beam was subjected to reversed loading at a constant strain. The strain was varied from $1 \%$ to $2.5 \%$ but was kept constant throughout the series of cycles applied to each individual beam. The number of cycles before fracture for a particular cyclic strain range are shown in Figure 16. From this graph the low cycle fatigue life at plus or minus $1 \%$ strain was 607 cycles while at plus or minus $2.5 \%$ strain the life had dropped to 16 cycles. Local buckling of the flanges was observed during the second half of the first cycle. Figure 17 shows the failure of a beam during the 16th cycle ( $\pm 2.5 \%$ strain) the result of the enlargement of cracks in the wrinkles caused by local buckling of the flanges.

Undoubtedly concrete encasement or other means of preventing local buckling would affect the low cycle fatigue life appreciably so long as the encasement itself remained intact.

As a result of these tests and others Popov (22) has drawn the following conclusions :

(1) The tests have demonstrated that both the moment-curvature and load deflection hysteresis loops are remarkably stable 
66

with respect to their shape. This implies that a practically constant amount of energy absorption can be depended upon per cycle at each level of strain.

(2) The tests have shown that the onset of flange buckling did not signal an immediate loss of moment capacity. Instead the load continues to increase independently of the buckling action. Neither did the severe buckling of flanges and web signal a collapse of the system but the buckles appear and then disappear cyclically until failure.

(3) The tests have demonstrated that both A. 36 and A.44I rolled steel specimens have a remarkable ability to withstand severe reverse loadings. Failure occurs only after a large number of complete reversals of extremely high strains.

Typical idealized hysteresis curves for various levels of strain are shown in Figure 18.

A problem which arises with cyclic load tests is the criteria for failure. Under the current weak beam-strong column concept the accumulated energy capacity may be the most realistic acceptance criteria for members and connections being a measure of the ability to dissipate energy in inelastic action for a number of cycles. In the tests mentioned the criteria for failure was that an increase in deflection was accompanied by a decrease in load within the current cycling amplitude. For the material and physical dimensions of the members tested this usually corresponded to fracture of the flanges, flange plates or welds.

\section{Connections}

\subsection{Requirements}

The weak beam - strong column approach requires the use of adequate connections between the elements of the structure to maintain full continuity, moment redistribution and energy absorption. In general most of the inelastic behaviour of the structure during an earthquake will occur at or near the joints. Hence connections must have the following fundamental requirements :

(1) Be adequate from a strength point of view;

(2) Have matching energy absorption capacity to the members joined.

other requirements for a satisfactory connection are :

(1) It should be simple and practical to fabricate:

(2) It should be economical;

(3) It should be of a type which produces as little stress concentration as possible hence reducing the chances of brittle fracture;
(4) It should meet the functional requirements of the building:

(5) In joining ductile elements a connection must not be used which creates an assembly which is brittle or non ductile;

(6) The connection must permit adequate access for both welding and inspection.

Types of joints which are used:

(a) Fully bolted or rivetted.

(b) Fillet welded.

(c) Butt welded.

(d) Combinations of any of the above.

Fully bolted or rivetted joints have been used in the past but the massive connections required to develop the moment capacity of the joined members as well as cost has tended against their continued use. Functional requirements also may preclude their use.

Generally the most satisfactory way of meeting the above criteria is by welding or a combination of welding and bolting.

Static tests have shown that fillet welded beam column connections including the use of moment plates can develop the full yield strength of the connected members. However in cyclically loaded tests discussed later the fillet welded connections performed poorly when compared to butt welded connections. This type of connection has been used in New Zealand in the past for some structures with steel frames.

\subsection{Tests on Connections}

Tests on three basic types of beam column connections subjected to repeated inelastic strain reversal have been reported by Popov and Pinkney (10). These tests were carried out in a similar manner to the low cycle fatigue tests discussed earlier. The three basic types of joints tested were:

(1) A butt welded joint in which the beam was welded direct to the column;-

(2) A fillet welded joint with moment plates;

(3) A high strength bolted joint with welded moment plates.

In all cases the columns were assumed to remain elastic. The three types of joints after failure are shown in Figures 19, 20 and 21. Failure was by fracture through the flanges or moment plates. The number of cycles to failure varied from $22 \frac{1}{2}$ to 120 for the butt welded connections with tip deflections up to $\pm 4 "$.

Using accumulated energy as the criteria for satisfactory performance it can be seen from Figure 22 that the butt welded connections were superior to the other types tested. This conclusion applies to both the mild steel and the high yield steel connections.

The conclusions arrived at by popov for members subjected to low cycle fatigue apply equally well to the tests on connections. 
Tests have also been carried out on steel connections in Japan but results are not freely available in English. A summary of some of these tests is reported in Reference 10.

\subsection{Design of Connections}

The design of connections located within the regions where plastic hinges are likely to form during earthquake motion should be on the basis of developing the full plastic moment capacity of the beam connected. Design methods for typical connections are shown in Figure 23 which is based upon a more complete review given in reference 23. The connections shown are for one or two way beam-column connections. For the case of four way beam-column connections with beams framing into the major and minor axes of a column the connections should be designed as two way connections. No allowance should be made for the fact that beams frame in from the other direction.

one aspect which has received little attention to date is the panel zone in the column at a beam-column connection. Little is known of the panel zones strength, stiffness and ductility under cyclic loading in spite of the fact that the panel zone plays an important part in the total inelastic deflection of a frame. The deformation of the panel zone is shown in an idealized manner in Figure 24. This problem has been discussed by Bertero (24) who suggested a programme of investigation into the inelastic behaviour of panel zones.

Beams framing into each side of the panel would have a marked effect on the inelastic performance of the panel. However until more is known it would seem prudent to use the design methods of Figure 23 applying to the panel zone in a conservative manner.

$$
\text { Beedle (25) has pointed out }
$$

the dificulties which arise with bolted joints in tension where the ratio of ultimate to yield in the material is close to unity.

For adequate service performance the usual design philosophy is to ensure yielding in the gross section of the plates prior to failure at the nett section through the holes or to fracture of the bolts. With joints of usual proportions and a steel with an ultimate to yield ratio of only 1.1, failure would occur in the nett section through the hole. The S.E.A.O.C. provisions, Section 2725, recognize this problem and require bolted beam connections to be away from regions where plastic hinges may form in the case of steels. with an ultimate less than 1.5 of the yield.

An indication of the relative cost of different types of connections are given in Figure $25(26)$ These are for U.S. shop conditions and it is assumed similar criteria apply in New Zealand.

It has been argued that welded connections likely to be highly stressed should be carried out in the shop and that field splices in areas of low stress may then be either
Eield welded or bolted. In line with this rather subjective approach are the reduction factors specified in Clause 9.4 of the M.O.W. Code of practice (27) applied to field welded joints and site bolted joints. As far as is. known these factors have no test or other basis. For adequately inspected welded joints there would seem to be no justification for down-grading field welds. If any reduction factors are justified it would seem from the tests above that these should be applied to fillet welded or bolted connections in comparison with butt welded connections either shop or field welded.

With proper field welding procedures and modern inspection techniques it would seem difficult to justify on economic or technical grounds the use of two joints where one would suffice. It is difficult to generalise, since costs will depend on the type of sections to be connected which may dictate a shop connection and field splice.

\section{Design Methods}

\subsection{General}

Methods currently available for the design of multi-storey frames are:

(1) Elastic design methods

(2) Ultimate strength design methods

(3) Plastic design methods (i) braced frames

(ii) unbraced frames.

\subsection{Elastic Design Methods}

Acceptable design methods for the design of structural steel frames subjected to earthquake ground motions are B.S. 499 (15)

with a $25 \%$ increase in allowable stresses and the A.I.S.C. Specification (6) which allows a $1 / 3$ increase in allowable stresses.

Normal methods of analysis may be used for gravity loads.

Additional detailed requirements mostly discussed in previous paragraphs are :

(1) Connections within the regions where plastic hinges will form should be designed to develop the full plastic properties of the member jointed (unless it can be shown that a lesser connection will suffice);

(2) Column splices should be designed to develop the full capacity of the member;

(3) Sections should be used which are acceptable for plastic design. Beams should have the following minimum properties to preclude early local buckling:
Flange Width Flange Thickness

\section{$36 \mathrm{Ksi}$}

50
17

14
Depth Web Thickness
70

60 
(4) Lateral bracing should comply with the requirements for plastic design (6).

(5) Columns should be designed with effective lengths which are based upon sidesway occuring.

Acceptable design curves are given in Reference 6.

Where welded built up column members are used a conservative approach to axial loads should be adopted because of the high level of residual stress.

Beedle (25) has discussed this problem and has pointed out the beneficial effects of stripping plates by gas prior to welding. It is fortunate that this corresponds with the usual practice of stripping universal flats prior to fabrication to remove rolling defects along the edges.

Column axial loads should be checked against the total shear strength of the members framing into the column.

\subsection{Ultimate Strength Design Methods}

Ultimate strength design methods may be used. However load factors are usually chosen to give stress levels about the same as for the elastic design method.

This method does have advantages in dealing with composite members of steel and concrete.

\subsection{Plastic Design Methods}

Plastic design methods are not generally recommended at this stage for the design of multi-storey frames subjected to earthquake ground motions although research on this problem has been underway for some time in the U.S.

As a matter of interest, three methods are available for the design of frames for gravity loads and wind. These cover braced and unbraced frames.

\section{(1) Braced Frames:}

(a) The Joint Committee report on rigid multi-storey welded steel frames (28)

(b) The A.I.S.I. manual on the plastic design of braced multi-storey steel frames (29);

\section{(2) Unbraced Frames:}

Two computer programmes are available for the preliminary design of unbraced multi-storey frames. Details are outlined in Reference 30.

\section{Workmanship and Welding Inspection}

\subsection{Workmanship}

Co-operation and exchange of ideas between designer, fabricator and technical consultants should commence as early as practicable and, if possible in the design phase.
General clauses relating to fabrication and erection are covered by Part 5 of B.S. 449: (15)

In order to achieve the accuracy required for erection of a multi-storey frame, the provision of jigs, trial assembly of important parts, the use of full scale mock-ups of joint details and feasibility studies on assembly procedures, may all be necessary.

on site, accurate rigging, constant checking of line and level, proper allowance for weld shrinkage effects on root gaps and column verticality and correct welding sequence must be kept constantly in mind.

\subsection{Welding Inspection}

The employment of welding requires programmes involving welder qualification tests. procedure tests where joints depart from the normal experience, and production tests. Such testing is usually backed up by non destructive testing methods in the shop and on the site, together with visual inspection to ensure quality control.

Methods of inspection covering welding are based upon four test methods:

(1) Visual

(2) Magnetic particles and dye penetrant

(3) Ultrasonics

(4) Radiography.

These are listed in increasing order of cost. Detection capabilities of these methods for various weld defects are listed in Table 3 .

The S.E.A.O.C. provisions (4) require a programme of non-destructive testing to be established by the engineer covering tension butt welded connections in primary members in the frame.

The suggested minimum frequency is; test all critical tension butt welds unless the rejection rate is consistently less than $5 \%$. If the rejection rate is consistently less than $5 \%$ the testing rate could be reduced to $25 \%$ of all welds.

No mention is made of welds other than in critical areas. For such non critical welds the testing rate should be about $10 \%$.

The fact that even under carefully controlled laboratory test conditions problems of weld defects can arise is highlighted in the tests reported by Popov and Pinkney (10)

Two connections of the series fabricated in a commercial shop and subjected to ultrasonic welding inspection were defective. In fact the joints were incorrectly prepared and the ultrasonic record misinterpreted.

Under cyclic loading the connections failed, in one case during the first cycle, and in the other case after 5 cycles. 


\section{Conclusions}

Steel, like any other structural material. has its advantages and its limitations. A decision on whether to use structural steel for a particular project requires a proper evaluation of such properties together with consideration of cost.

once the use of steel has been decided upon, the question of type of steel, mechanical properties, notch ductility, and weldability must be considered against the background of structural concept, fabrication and erection.

It is quite evident that a considerable amount of research and development is still required in the field of steel seismic design. The application of plastic design or some other limit design to ductile moment resisting space frames and methods to allow for composite action between concrete and steel require considerable work before they become practical. design methods. In the field of material properties and construction details, problems of brittle fracture, low cycle fatigue (at high strains) of members and connections, and the rotation capacity of actual members and connections under cyclic reversed loading including the effect of strain rate, only a limited amount of research appears to have been carried out and published in the technical literature.

It would seem appropriate to repeat the statement in the introduction that structural steel will not, in itself, ensure adequate performance of a structure. Careful attention must be paid to structural concept, selection and testing of materials, adequate design of connections and competent workmanship and inspection procedures for quality control.

\section{REFERENCES}

1. Park, R. (1968) "Ductility of Reinforced Concrete Frames Under Seismic Loading" N.Z. Engineering 23 (11) 15 November 1968.

2. - (1967) "The Prince William Sound Alaska Earthquake of 1964 and Aftershocks" Volume II Part A U.S. Department of Commerce.

3. Wolfram, H.G. (1965) "Welded Beam - Column Connections for Multi-Storey Buildings" Proc. 13th Nat. Conventions Australian Welding Institute.

4. - (1968) "Recommended Lateral Force Requirements and Commentary" S.E.A.O.C.

5. Calambos, T.V. (1968) "Deformation and Energy Absorption Capacity of steel Structures in the Inelastic Range" A.I.S.I. Steel Research for Construction Bulletin No. 8. March 1968.

6. - (1969) "Specification for the Design, Fabrication and Erection of Structural Steel for Buildings" A.I.S.C.

7. Lay \& Galambos, T.V. (1967) "Inelastic Beams Under Moment Gradient" Journal of the Structural Division A.S.C.E. Vol. 93, No. ST1, Paper 5110, February 1967.

8. Lukey, A.F. \& Adams, P.F. (1969) "Rotation Capacity of Beams Under Moment Gradient" Journal of the Structural Division A.S.C.E. Vol. 95, No. St6, Paper 6599. June 1969.

9. Bertero, V.V. \& Popov, E.P. (1965) "Effect of Large Alternating Strains on steel Beams" Journal of the Structural Division A.S.C.E. Vol. 91, No. STl, Paper 4217. February 1965.

10. Popov, E.P. \& Pinkney, R.B. (1967) "Behaviour of Steel Building Connections Subjected to Repeated Strain Reversal" S.E.S.M. 67-30 University of California December 1967.

11. - (1968) B.S. 4360: 1968 "Specification for Weldable Structural Steels" British Standards Institution.

12.

(1964) B.S. 1856: 1964 "Specification of General Requirements for the Metal Arc Welding of Mild Steel" British Standards Institution.

13. - (1965) B.S. 2642: 1965 "Specifications of General Requirements for the Arc Welding of steel to B.S. 968 and Similar steels" British Standards Institution.

14. Fisher, J.W. \& Driscoll, G.C. (1959) "Corner Connections Loaded in Tension" Welding Research Supplement to the Welding Journal November 1959.

15. - (1959) B.S. 449: 1959 "Specification for the Use of Structural Steel in Building" British Standards Institution.

16. O'Connor, C. (1969) "Structural Implications of Fracture Tests on Al Steel" The Institution of Engineers Australia Civil Engineering Transaction April 1969. 
17. Alting, T.J. (1968) "Post war Developments in Shipbuilding Steels" Acier-Stahl-steel No. 12. 1968.

18. - (1966) Proceedings of the conference on Structural Steelwork B.C.S.A. P.20.

19. Tipper, C.F. (1962) "The Brittle Fracture Story" Cambridge University Press P.173.

20. Pellini, W.S. \& Puzak, P.O. (1963) N.R.I. Report 5920 March 1963, U.S. Office of Naval Research.

21. Gurney, T.R. (1968) "The Fatigue of Welded Structures" Cambridge University Press P.I85.

22. Popov, E.P. (1967) Initial Draft of Section 6.4 "Commentary on Plastic Design in steel" A.S.C.E. Manual No. 41, 1961 (Proposed Revision).

23. Driscoll, G.C. etal (1965) "Plastic Design of Multi-Storey Frames" Lehigh University.

24. Bertero, V.V. (1969) "Seismic Behaviour of Steel Beam to Column Connection Subassemblages" 4th world Conference Earthquake Engineering, Chile 1969.

25. Heyman, J. \& Leckie, F.A. (1968) "Engineering Plasticity" Cambridge University Press, $p \cdot p \cdot 47$ and 54 .

26. Shields, D.C. (1968) "Cost Factors in Structural Steel" Proceedings 37 th Annual Convention S.E.A.O.C.

27. - (1968) P.W.81/10/1: 1968 Code of Practice "Design of Public Buildings" December 1968, M.O.W., New Zealand.

28. - (1964) "Fully Rigid Multi-Storey Welded Steel Frames" Joint Committee Report, The Institution of Structural Engineers. The Institute of Welding, December 1964.

29. - (1968) "Plastic Design of Braced Multi-Storey Steel Frames" A.I.S.I. I968.

30. Driscoll, G.C.. Armacost, J.O., Hansell, W.C. (1970) "Plastic Design of Multi-Storey Frames by Computer" Journal of the Structural Division A.S.C.E. Vol. 96, No. ST1, Paper 6995, January 1970.

31. Popov, E.P.\& Pinkney, R.B. (1969) "Reliability of Steel Beam - Column Connection Under Cyclic Loading" 4th World Conference on Earthquake Engineering. Chile 1969. 


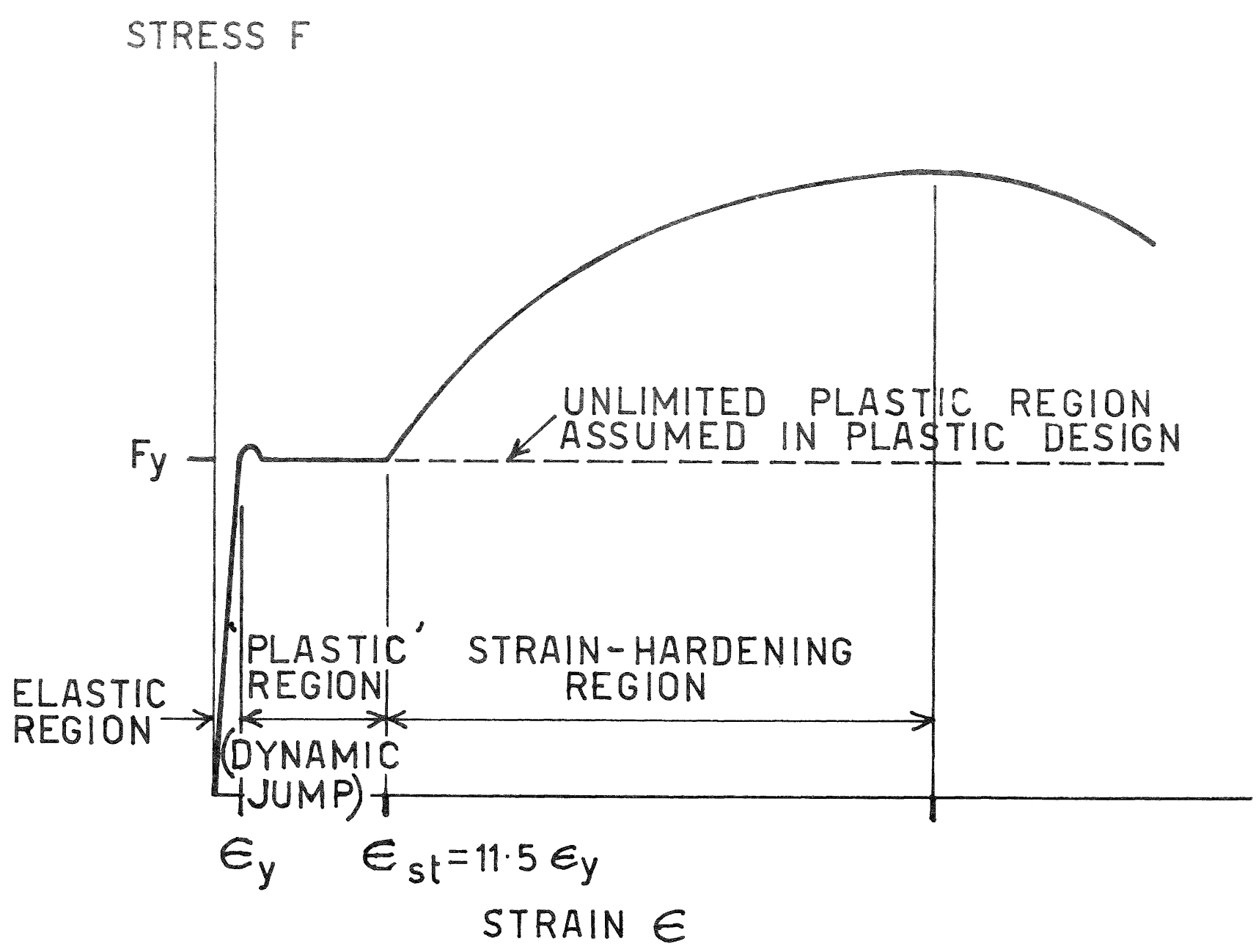

Fig. 1-Idealized Stress Strain Curve for Steel

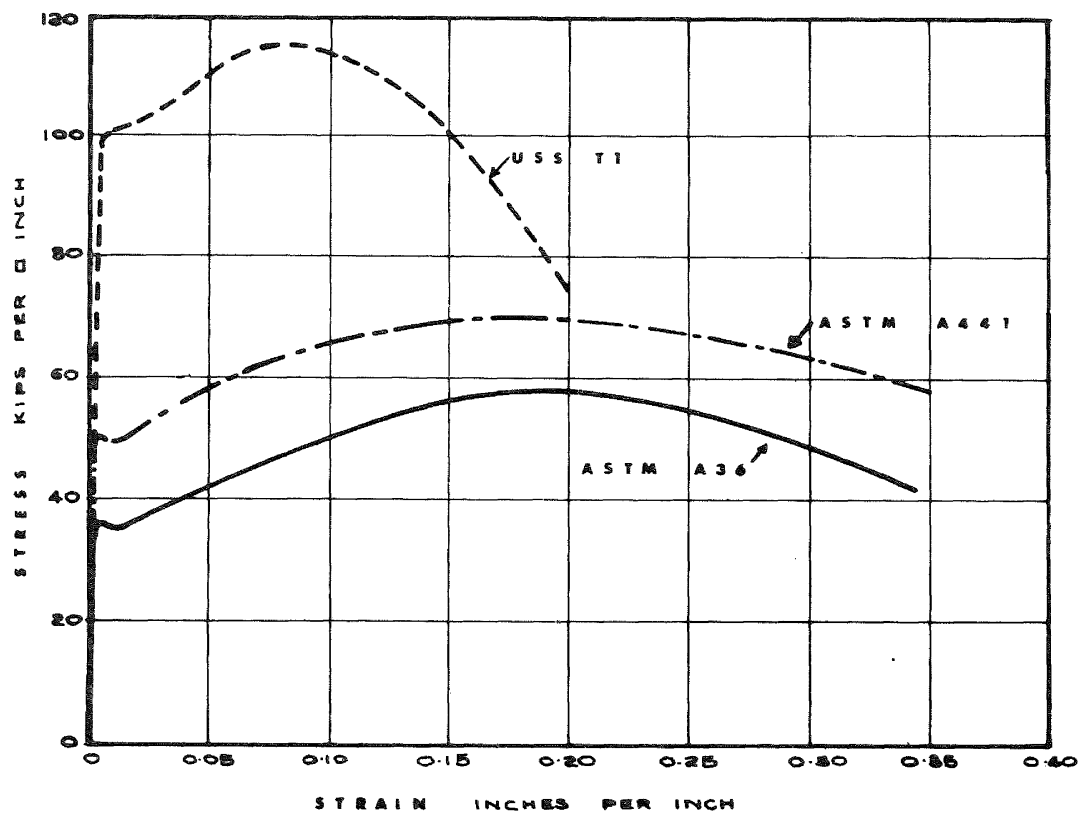

Fig. 2-Comparison of Stress-Strain Curves 

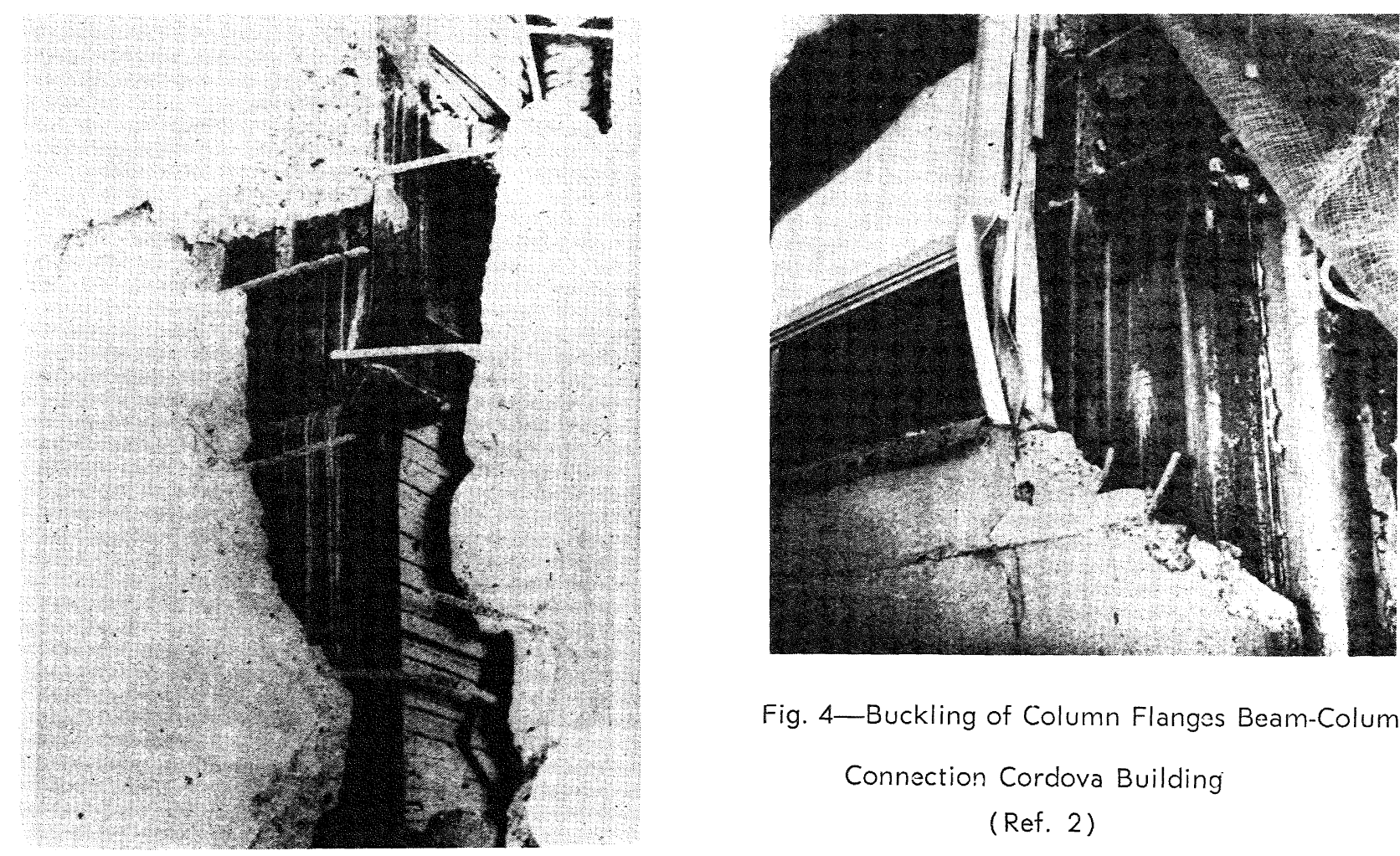

Fig. 4-Buckling of Column Flanges Beam-Column Connection Cordova Building

(Ref. 2)

Fig. 3-Fractures in Flanges of Corner Column Column A.6 Cordova Building (Ref. 2)

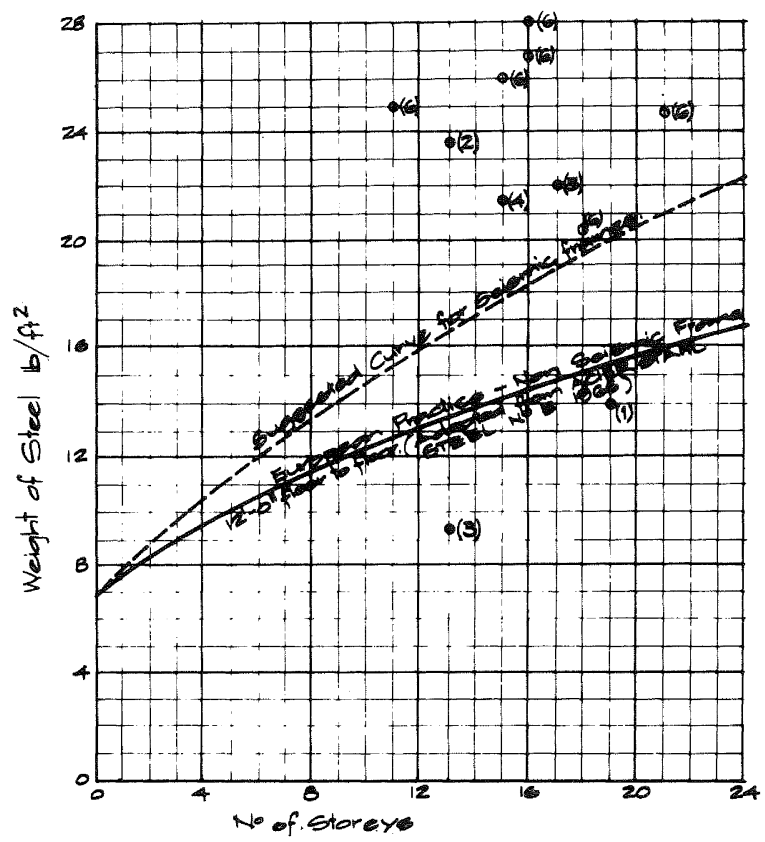

Fig. 5-Weight of Steel per square foot for various numbers of Storeys 


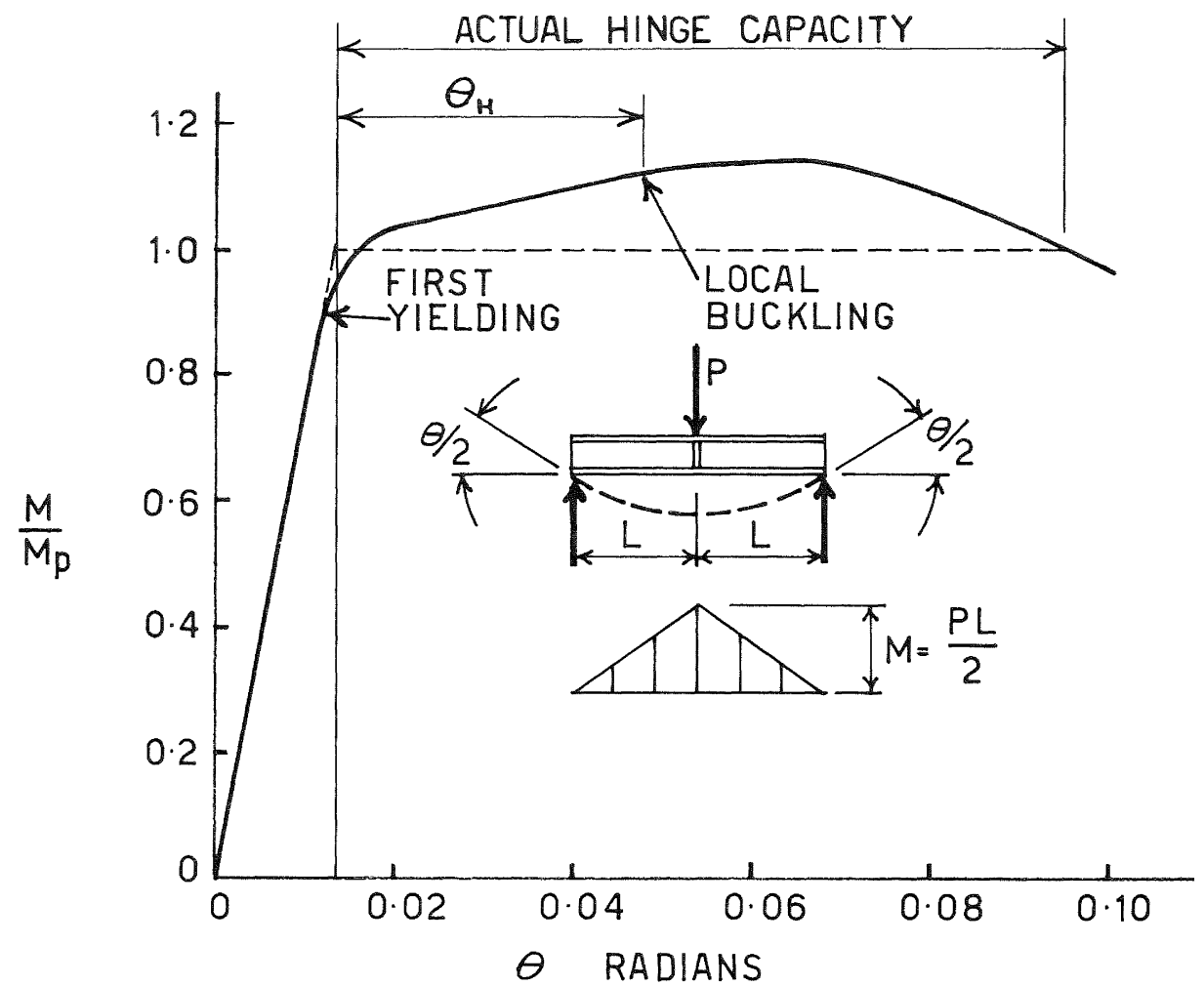

Fig. 6-Idealized Moment-Curvature Relationship Universal Beam Section (Ref. 8)

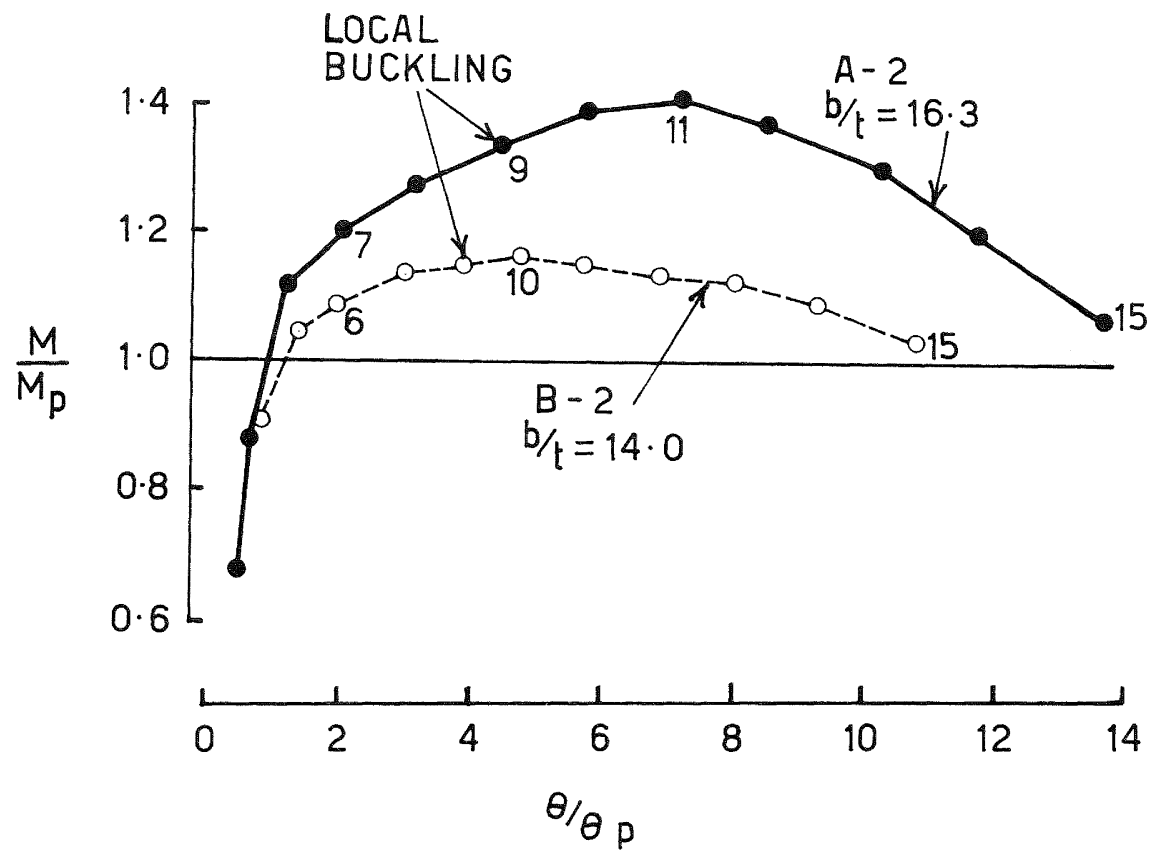

Fig. 7-Typical Moment-Curvature Universal Beams Under Moment Gradient (Ref. 8) 


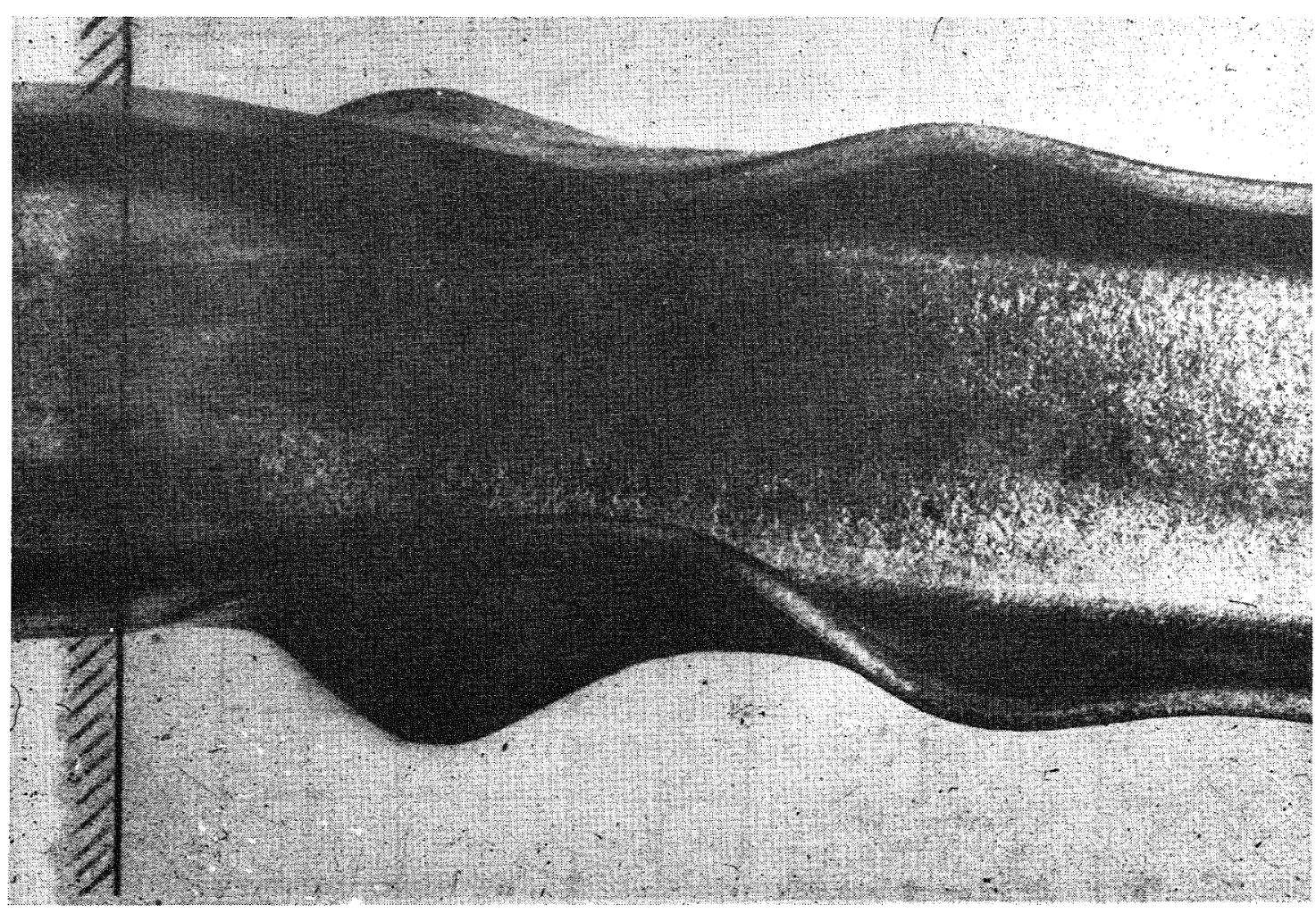

Fig. 8-Typical Local Buckling of Flanges (Ref. 9)

\section{DUCTILITY FACTOR :}

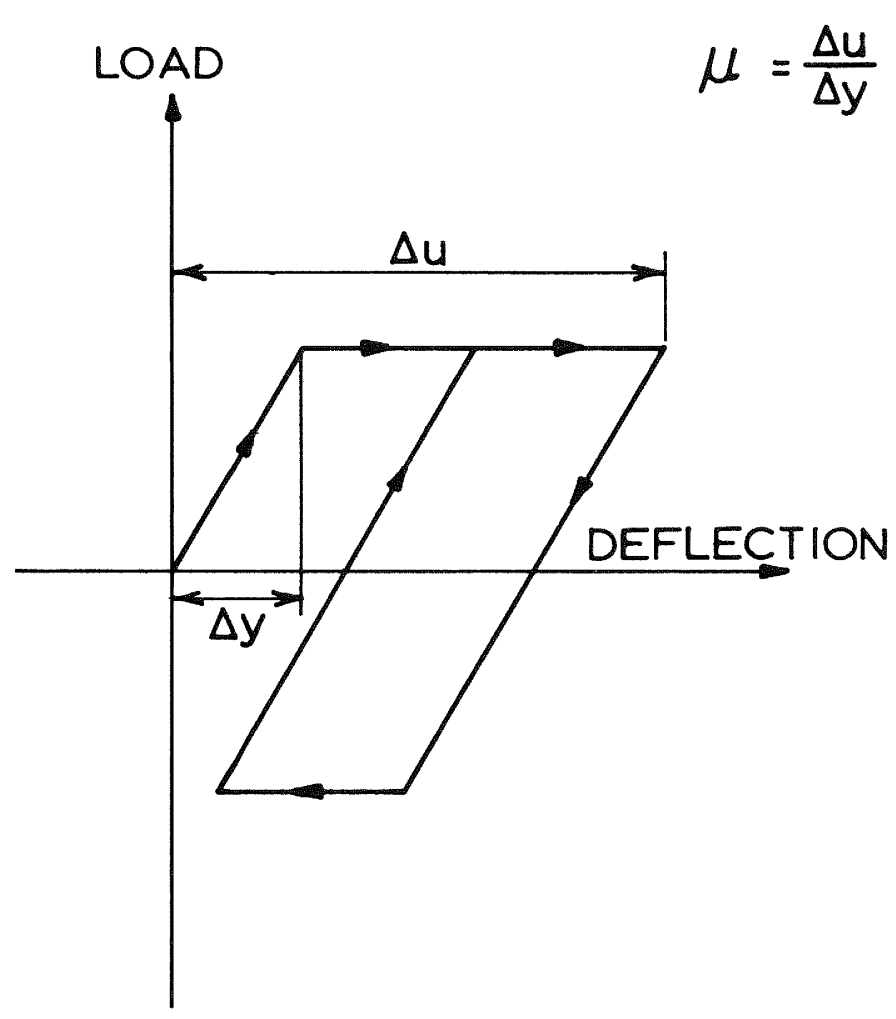

Fig. 9a-Ordinary Elasto-Plastic Model

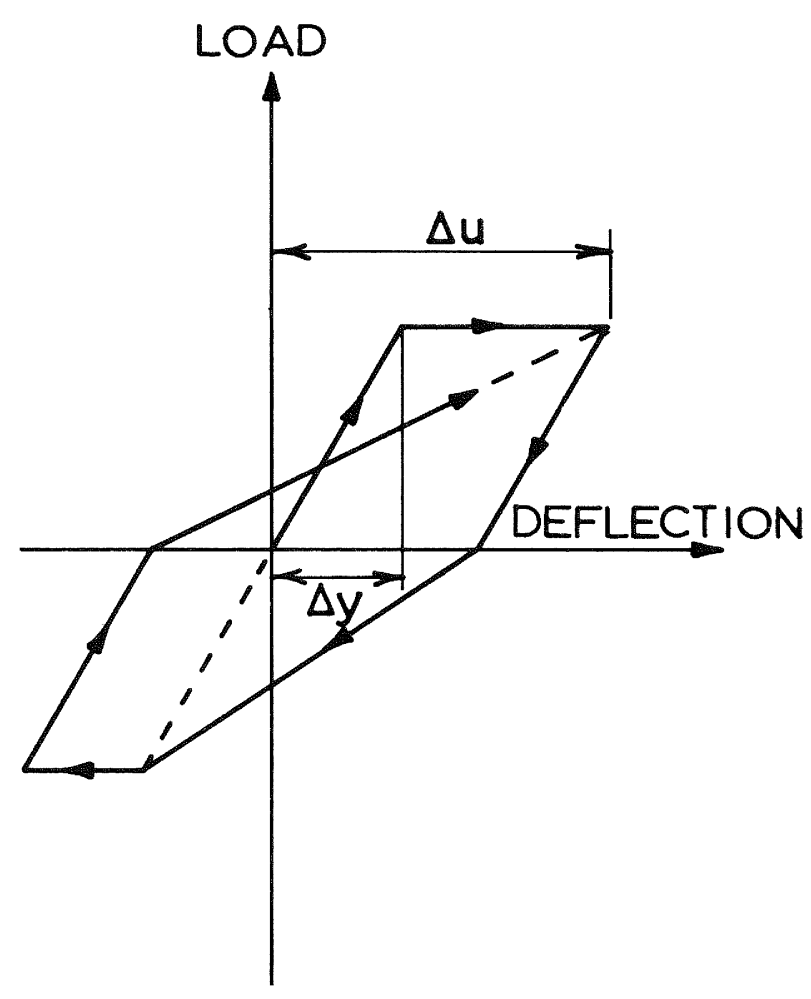

Fig. 9b-Ordinary Degrading Stiffness Model 


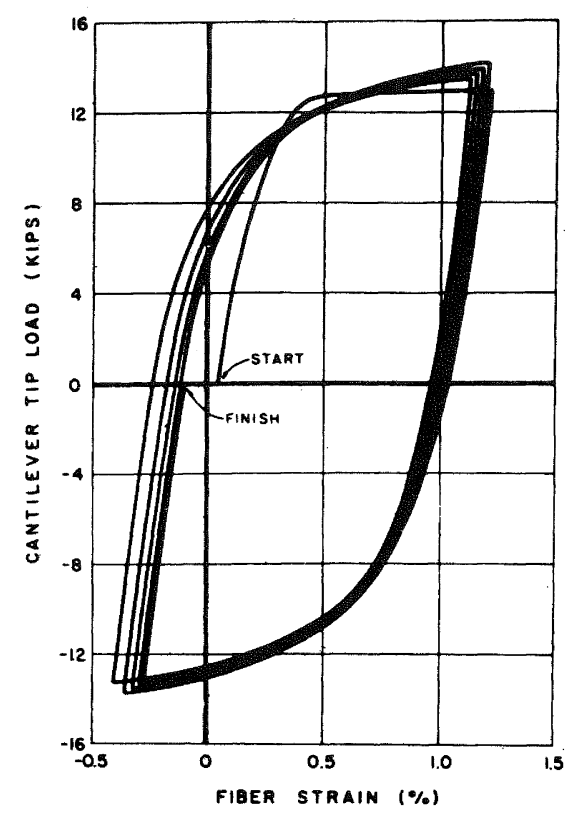

Fig. 10-Stability of Hysteresis Loops at $\pm 1 \%$ Nominal Control Strain (Ref. 10)

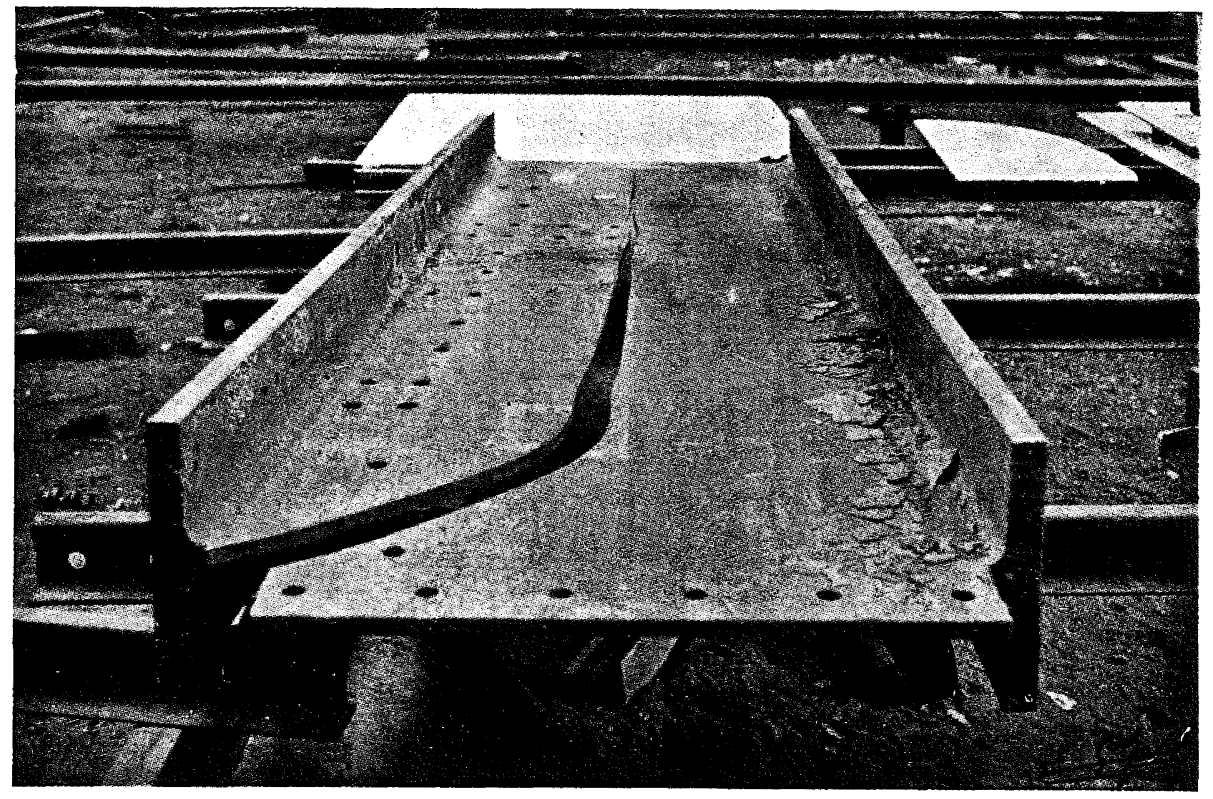

Fig. 11-Spontaneous Failure of a Steel Beam in the Brittle Fracture Mode (Torroja) 

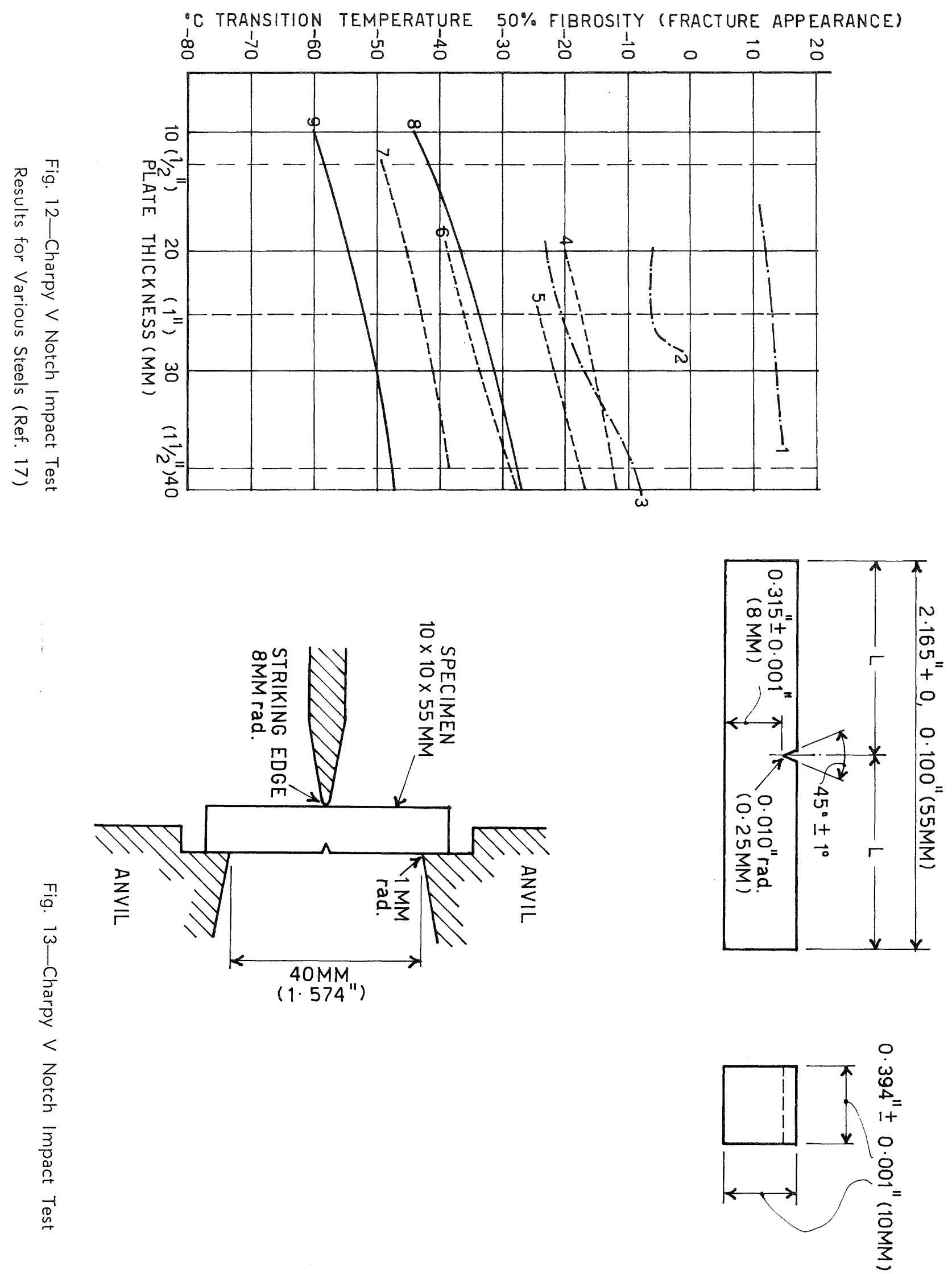


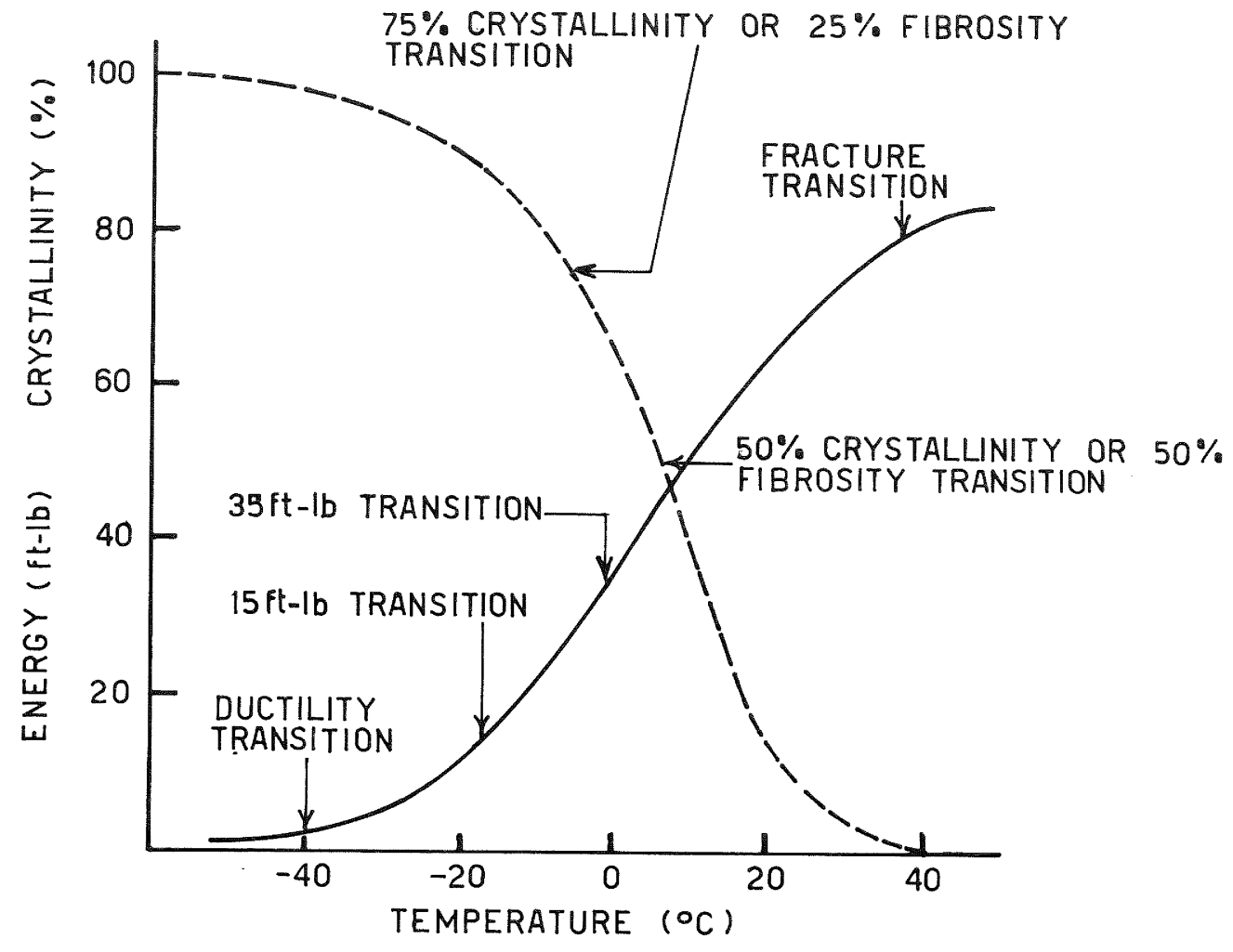

Fig. 14-Idealized Charpy $\vee$ Notch Test Results

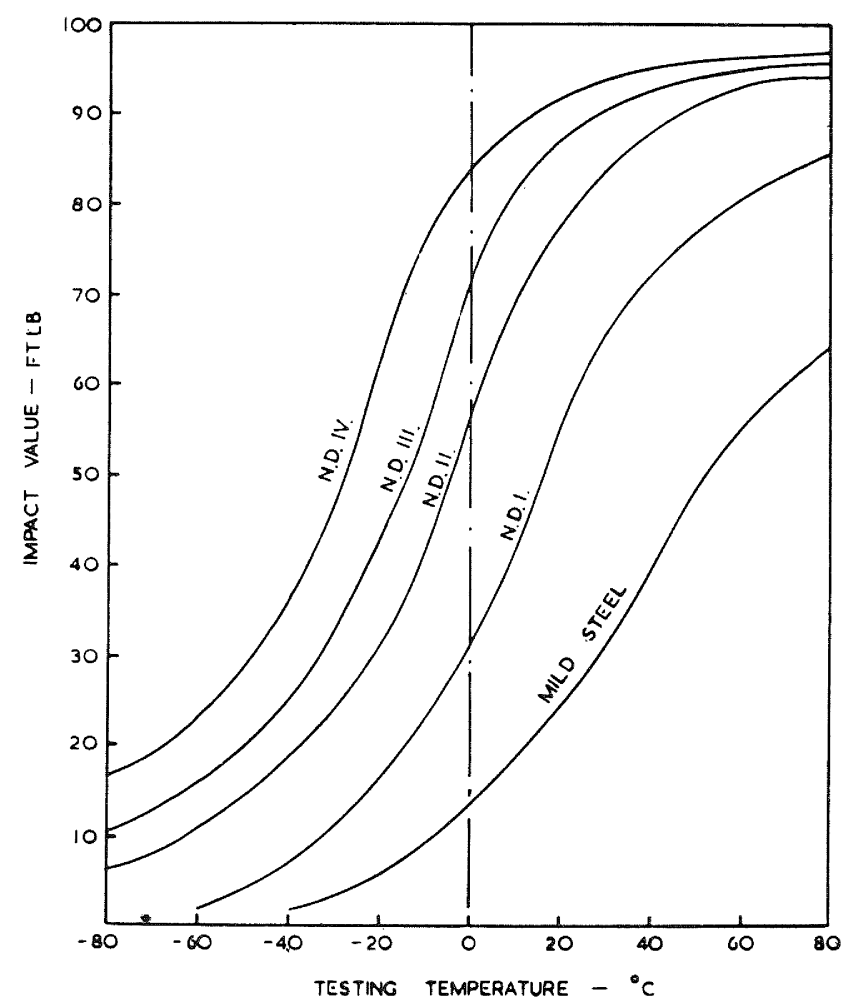

Fig. 15-Typical Charpy $\vee$ Notch Impact Curves for 1 " Thick Plate (Ref. 18) 


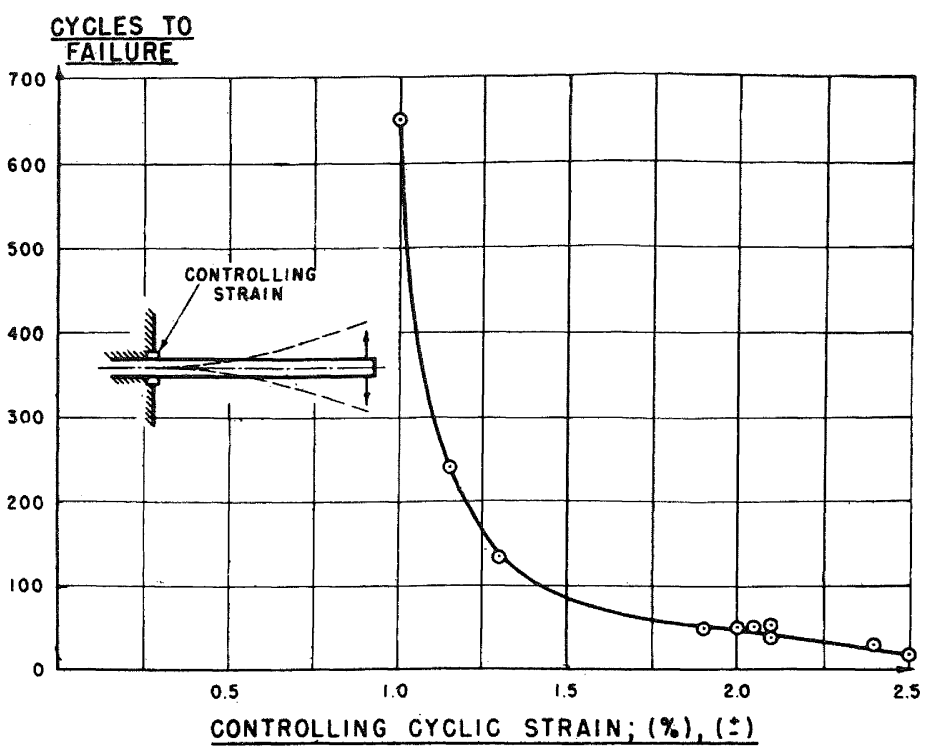

Fig. 16-No. of Cycles Required to Attain Fracture as a Function of the Controlling Cyclic Strain (Ref. 9)

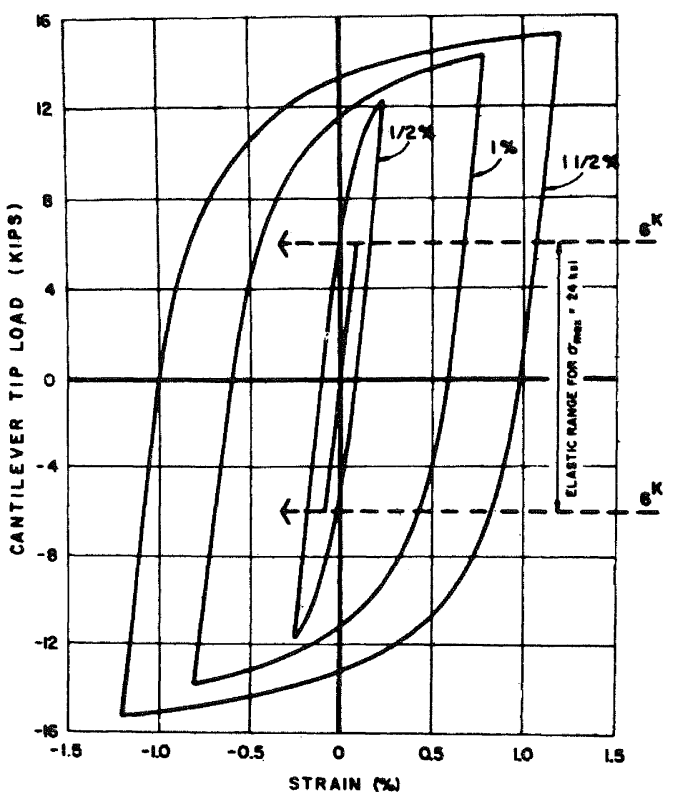

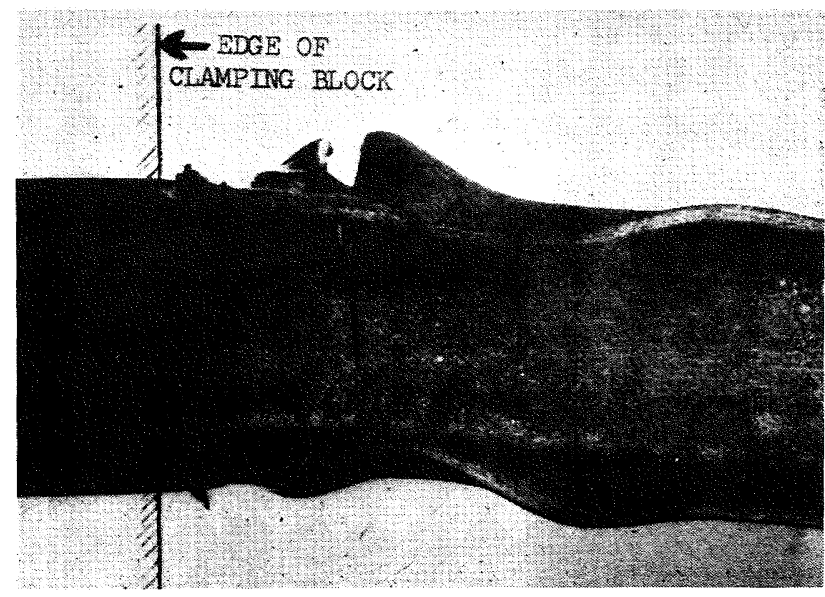

Fig. 17-Fracture During 16th Cycle at $\pm 2.5 \%$ Controlling Strain (Ref. 9)

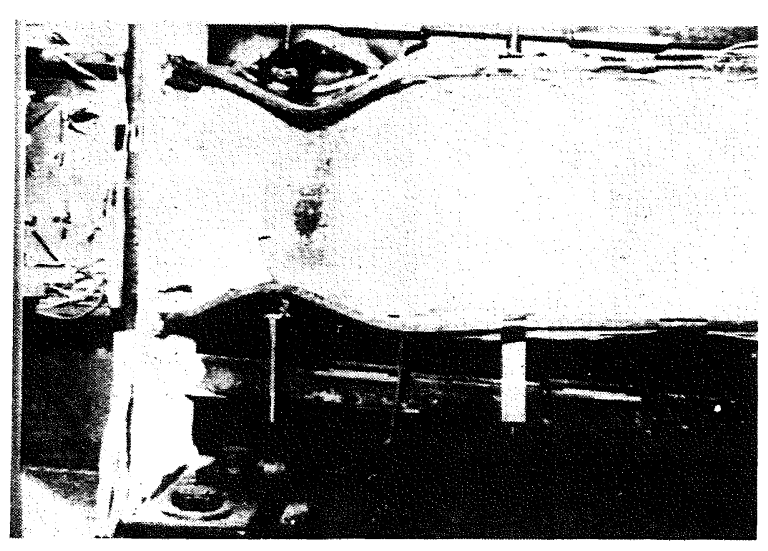

Fig. 19-Butt Welded Specimen at Failure (Ref. 10)

Fig. 18-Load-Control Strain Hysteresis Loops (Ref. 10) 


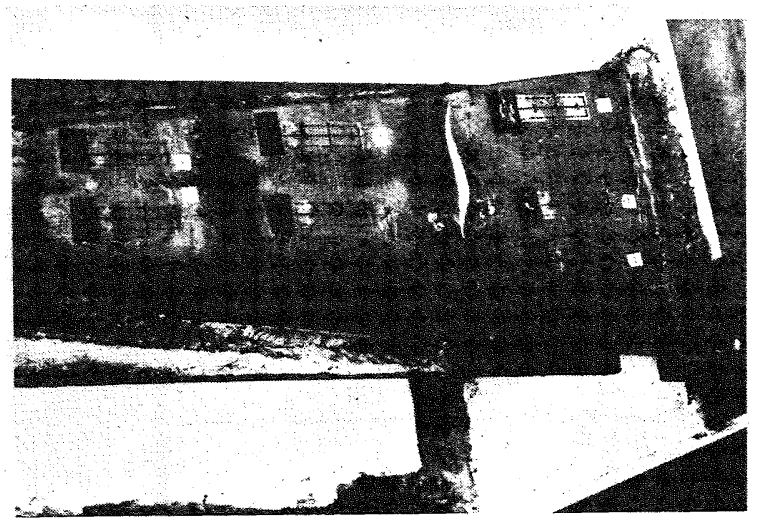

Fig. 20_Fillet Welded Specimen at Failure (Ref. 10)

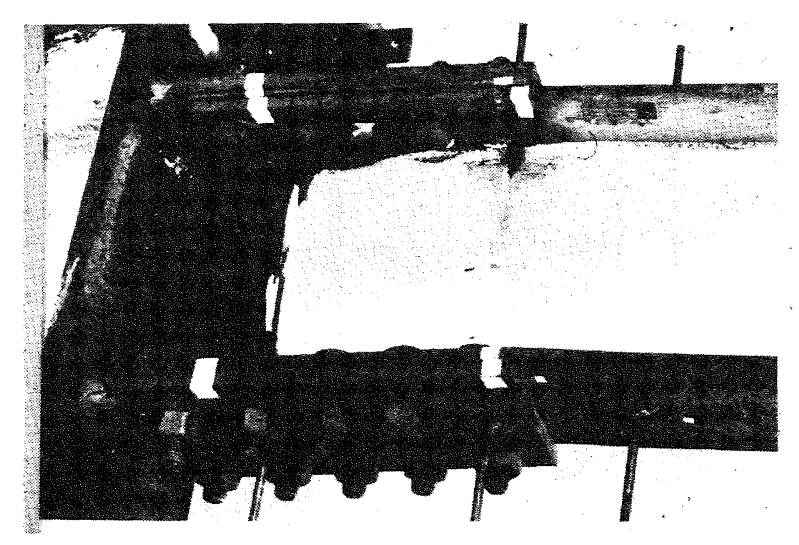

Fig. 22-Bolted Joint Specimen at Failure (Ref. 10)

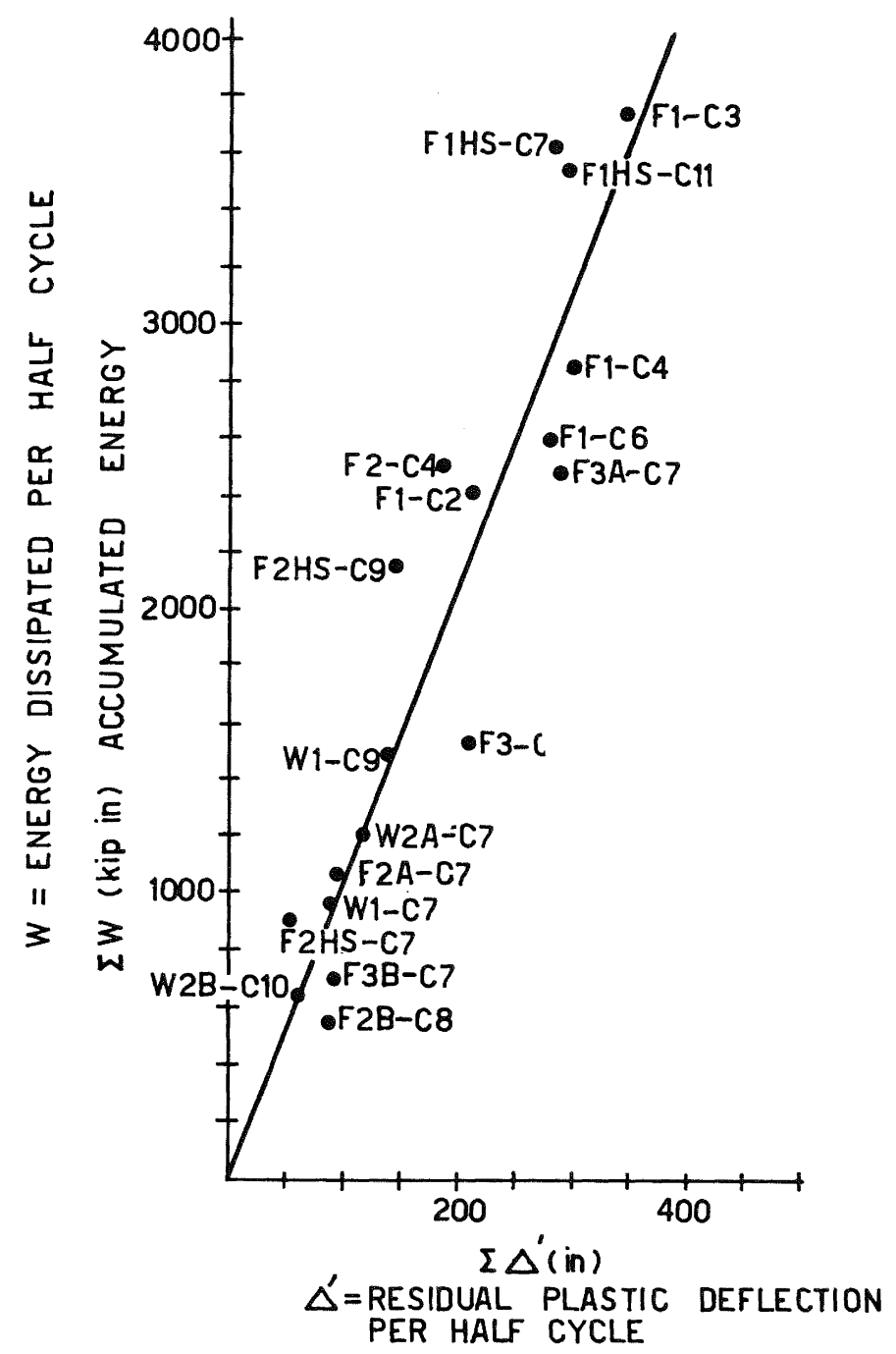

SERIES: CONNECTION:

F2 BUTT WELD : COLUMN FLANGE

F2 FILLET WELD: COLUMN FLANGE

F3 BOLTED : COLUMN FLANGE

WI BUTT WELD : COLUMN WEB

W2 FILLET WELD: COLUMN WEB

$H S=H I G H$ YIELD STEEL

Fig. 21-Accumulated Energy versus Accumulated $\Delta^{\prime}$ (Ref. 31 ) 

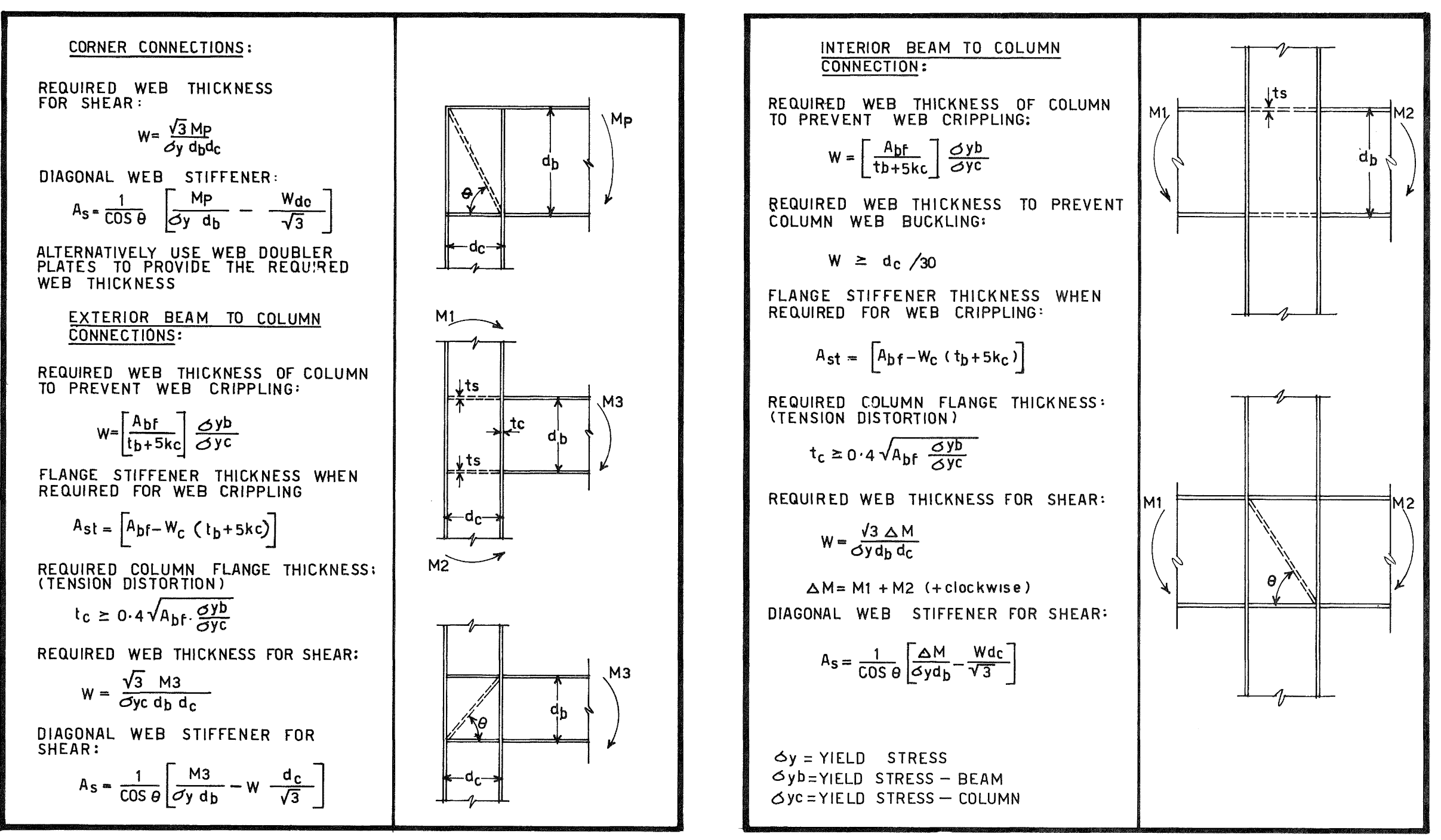

Fig. 23-Design of Beam Column Connections (Ref. 23) 


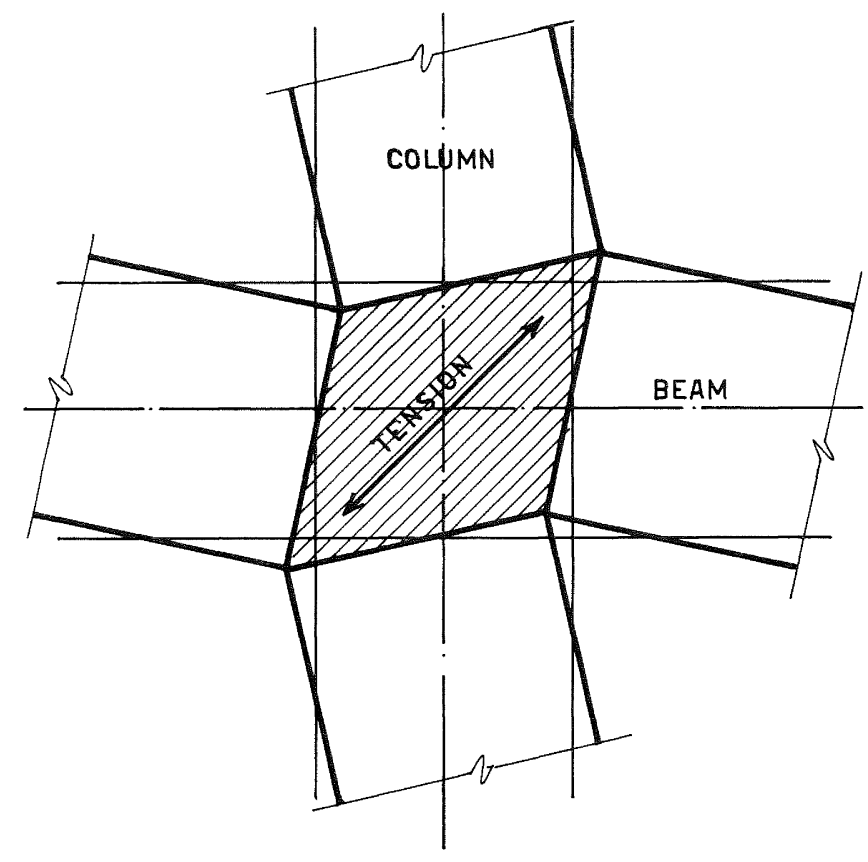

Fig. 24-Panel Zone Deformation
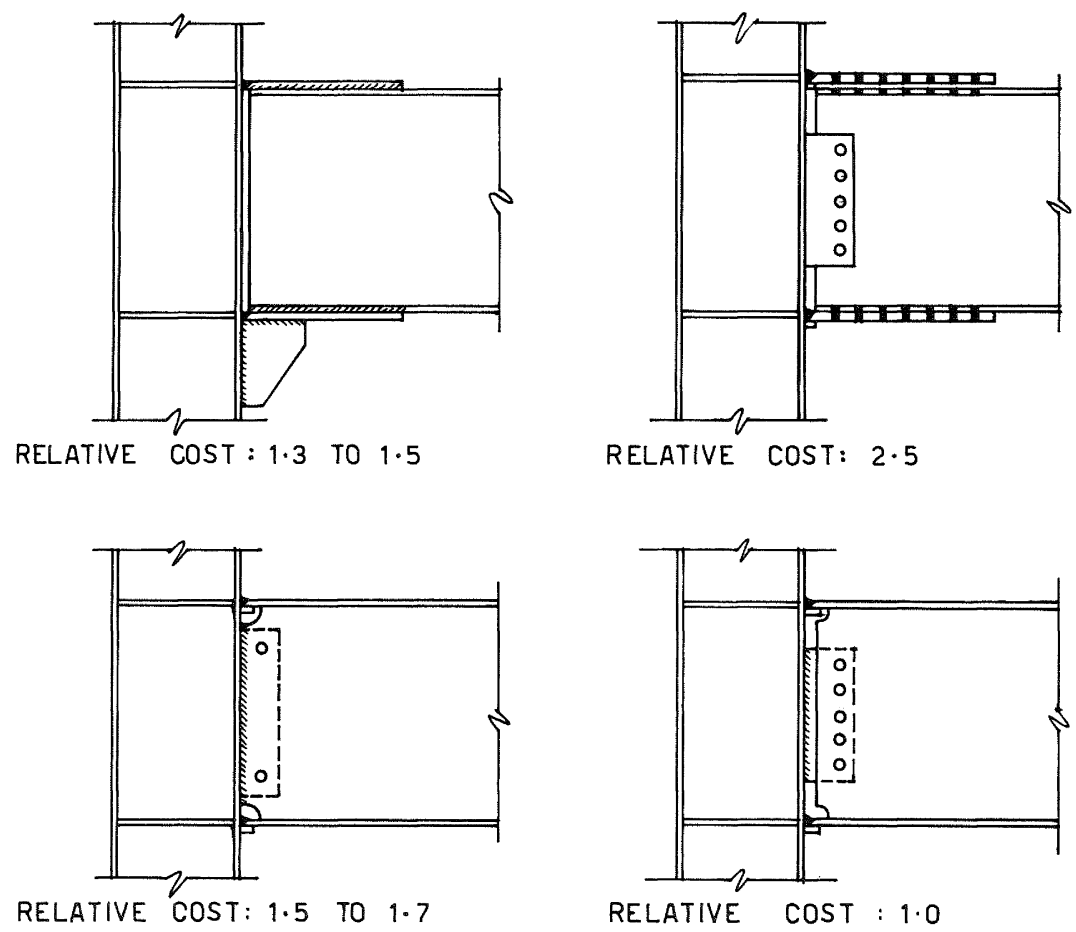

Fig. 25-Relative Cost of Beam Column Connections (Ref. 25) 
TABLE 1

\begin{tabular}{|c|c|c|c|c|c|c|c|}
\hline GRADE & $\begin{array}{l}\text { Mn/C } \\
\text { LADLE }\end{array}$ & $\begin{array}{l}\text { CARBON } \\
\text { EQUIV. } \\
\text { (If agreed) } \\
\%\end{array}$ & $\begin{array}{c}\text { ELONG. } \\
\text { 8"GL } \\
\%\end{array}$ & $\begin{array}{l}\text { TENSILE } \\
\text { STRENGTH } \\
\text { ton } / \mathrm{in}^{2}\end{array}$ & $\begin{array}{l}\text { YIELD } \\
\text { STRENGTH } \\
\text { ton } / \text { in. }\end{array}$ & \multicolumn{2}{|c|}{$\begin{array}{c}\text { CHARPY V NOTCH } \\
\text { IMPACT TEST } \\
{ }^{\circ} \mathrm{C} \quad \mathrm{ft.lb} .\end{array}$} \\
\hline $40 \mathrm{~A}$ & - & - & 22 & $26 / 31$ & - & - & - \\
\hline B & $7 \cdot 5$ & - & 22 & $26 / 31$ & $13 \cdot 5 / 15 \cdot 0$ & R T & 20 \\
\hline C & $8 \cdot 3$ & 0.41 & 22 & $26 / 31$ & $13 \cdot 5 / 15 \cdot 0$ & 0 & 20 \\
\hline$D$ & $9 \cdot 4$ & 0.41 & 22 & $26 / 31$ & $14 \cdot 5 / 17 \cdot 0$ & $\begin{array}{l}-10 \\
-20\end{array}$ & $\begin{array}{l}30 \\
20\end{array}$ \\
\hline$E$ & 9.4 & 0.39 & 22 & $26 / 31$ & $14 \cdot 5 / 17 \cdot 0$ & {$\left[\begin{array}{r}-30 \\
-30 \\
-50\end{array}\right.$} & $\begin{array}{r}45 \\
35 \\
\end{array}$ \\
\hline $43 \mathrm{Al}$ & - & - & 20 & $28 / 33$ & - & - & - \\
\hline A & - & - & .20 & $28 / 33$ & $14 \cdot 0 / 16 \cdot 0$ & - & - \\
\hline B & $6 \cdot 8$ & - & 20 & $28 / 33$ & $14 \cdot 0 / 16 \cdot 0$ & RT & 20 \\
\hline c & $8 \cdot 3$ & 0.41 & 20 & $28 / 33$ & $14 \cdot 5 / 18 \cdot 0$ & $\Gamma \begin{array}{r}0 \\
-10\end{array}$ & $\begin{array}{l}20 \\
30\end{array}$ \\
\hline$D$ & $9 \cdot 4$ & 0.41 & 20 & $28 / 33$ & $15 \cdot 5 / 18 \cdot 0$ & $\begin{array}{l}-20 \\
=-20\end{array}$ & 20 \\
\hline$E$ & $9 \cdot 4$ & 0.39 & 20 & $28 / 33$ & $15 \cdot 5 / 18.0$ & {$\left[\begin{array}{l}-30 \\
-50 \\
\end{array}\right.$} & $\begin{array}{l}35 \\
20 \\
\end{array}$ \\
\hline $50 \mathrm{~A}$ & 6.9 & - & 18 & $32 / 40$ & - & - & - \\
\hline B & $7 \cdot 5$ & - & 18 & $32 / 40$ & $21 / 23$ & - & - \\
\hline$c$ & $7 \cdot 5$ & $0.45 / 0.47$ & 18 & $32 / 40$ & $21 / 23$ & {$\left[\begin{array}{l}-5 \\
-15\end{array}\right.$} & $\begin{array}{l}30 \\
20\end{array}$ \\
\hline$D$ & $8 \cdot 3$ & 0.43 & 18 & $32 / 40$ & $22 / 23$ & {$\left[\begin{array}{l}-20 \\
-30\end{array}\right.$} & $\begin{array}{r}30 \\
20 \\
\end{array}$ \\
\hline $55 C$ & $7 \cdot 3$ & 0.51 & 17 & $36 / 45$ & $27 / 29$ & {$\left[\begin{array}{r}0 \\
-20\end{array}\right.$} & $\begin{array}{l}20 \\
45\end{array}$ \\
\hline$E$ & $7 \cdot 3$ & 0.51 & 17 & $36 / 45$ & $26 / 29$ & {$\left[\begin{array}{l}-30 \\
-50\end{array}\right.$} & $\begin{array}{l}35 \\
20\end{array}$ \\
\hline
\end{tabular}

CHEMICAL COMPOSITION \& MECHANICAL PROPERTIES FOR PLATE (ABBREVIATED) 
TABLE 2

\begin{tabular}{|c|c|c|c|c|}
\hline $\begin{array}{l}\text { No } \\
\text { ON } \\
\text { GRAPH }\end{array}$ & TYPE OF STEEL & $\begin{array}{l}\text { AVERAGE } \\
\text { ANALYSIS } \\
(\%)\end{array}$ & $\frac{M n}{C}$ & OF $N^{\circ}$ \\
\hline 1 & $\begin{array}{l}\text { STEEL } 41 \text { SEMI-KILLED AS } \\
\text { ROLLED }\end{array}$ & $\begin{array}{l}0.17 \mathrm{C} \\
0.78 \mathrm{Mn}\end{array}$ & $4 \cdot 6$ & 29 \\
\hline 2 & $\begin{array}{l}\text { STEEL } 41 \text { SEMI-KILLED } \\
\text { CONTROLLED ROLLING }\end{array}$ & $\begin{array}{l}0.17 \mathrm{C} \\
0.81 \mathrm{Mn}\end{array}$ & $4 \cdot 8$ & 123 \\
\hline 3 & $\begin{array}{l}\text { STEEL } 41 \text { SEMI-KILLED } \\
\text { CONTROLLED ROLLING }\end{array}$ & $\begin{array}{l}0.13 \mathrm{C} \\
1.12 \mathrm{Mn}\end{array}$ & $8 \cdot 6$ & 154 \\
\hline 4 & $\begin{array}{lll}\text { STEEL } 41 & \text { A1 } & \text { KILLEED } \\
\text { CONTROLLED } & \text { ROLLING }\end{array}$ & $\begin{array}{l}0.165 \mathrm{C} \\
0.84 \mathrm{Mn}\end{array}$ & $5 \cdot 1$ & 8 \\
\hline 5 & $\begin{array}{l}\text { STEEL } 41 \text { A1 KILLED } \\
\text { NORMALISED }\end{array}$ & $\begin{array}{l}0.17 \mathrm{C} \\
0.84 \mathrm{Mn}\end{array}$ & $4 \cdot 9$ & 114 \\
\hline 6 & $\begin{array}{l}\text { STEEL } 41 \text { A1 } \\
\text { CONTLLELDED } \\
\text { ROLLING }\end{array}$ & $\begin{array}{l}0.11 \mathrm{C} \\
1 \cdot 20 \mathrm{Mn}\end{array}$ & $10 \cdot 9$ & 17 \\
\hline 7 & $\begin{array}{l}\text { STEEL } 41 \text { A1 KILLED } \\
\text { NORMALISED }\end{array}$ & $0.14 \mathrm{C}$ & $7 \cdot 7$ & 15 \\
\hline 8 & $\begin{array}{l}\text { STEEL } 52 \text { A1-Si-KILLED } \\
\text { NORMALISED }\end{array}$ & $\begin{array}{l}0.19 \mathrm{C} \\
1.34 \mathrm{Mn} \\
(0.32 \mathrm{Si})\end{array}$ & $7 \cdot 1$ & 27 \\
\hline 9 & $\begin{array}{l}\text { STEEL } 52 \text { WITH N N AI-Si- } \\
\text { KILLED CONTROLLED } \\
\text { ROLLING NORMALISED }\end{array}$ & $\begin{array}{l}0.15 \mathrm{C} \\
1.43 \mathrm{Mn} \\
(0.33 \mathrm{Si})\end{array}$ & $9 \cdot 5$ & 28 \\
\hline
\end{tabular}

Fig. 12-Charpy $\vee$ Notch Impact Test Results for Various Steels (Ref. 17)

\begin{tabular}{|l|c|c|c|c|}
\hline \multicolumn{1}{|c|}{ DEFECT } & VISUAL & $\begin{array}{c}\text { MAG. PART. } \\
\text { DYE PENE. }\end{array}$ & ULTRASONICS & RADIOGRAPHY \\
\hline 1. POROSITY & N.A. & N.A. & FAIR TO GOOD & EXCELLENT \\
\hline 2. INCLUSIONS & N.A. & N.A. & FAIR TO GOOD & EXCELLENT \\
\hline 3. LACK OF FUSION & N.A. & N.A. & EXCELLENT & FAIR \\
\hline 4. INCOMPLETE PENETRATION & N.A. & N.A. & EXCELLENT & GOOD \\
\hline 5. CRACKS & GOOD & V. GOOD & EXCELLENT & GOOD \\
TOE & N.A. & N.A. & GOOD & GOOD \\
LONGITUDINAL & GOOD & V. GOOD & EXCELLENT & POOR \\
TRANSVERSE & GOOD & V. GOOD & GOOD & FAIR \\
\hline 6. UNDERCUT & EXCELLENT & N.A. & N.A. & GOOD \\
\hline 7. OVERLAP & EXCELLENT & GOOD & N.A. & POOR \\
\hline 8. INCORRECT PROFILE & EXCELLENT & N.A. & N.A. & FAIR \\
\hline 9. SURFACE APPEARANCE & EXCELLENT & N.A. & N.A. & FAIR \\
\hline
\end{tabular}

WELD DEFECTS - DETECTION CAPABILITIES VARIOUS NON DESTRUCTIVE TESTS 